\title{
Diversity of hydrolases from hydrothermal vent sediments of the Levante Bay, Vulcano Island (Aeolian archipelago) identified by activity-based metagenomics and biochemical characterization of new esterases and an arabinopyranosidase
}

\author{
Antonio Placido $^{1} \cdot$ Tran Hai $^{2} \cdot$ Manuel Ferrer $^{3}$ - Tatyana N. Chernikova ${ }^{2}$. \\ Marco Distaso $^{2}$ - Dale Armstrong ${ }^{2}$ - Alexander F. Yakunin ${ }^{4}$ - Stepan V. Toshchakov ${ }^{5}$ \\ Michail M. Yakimov ${ }^{6}$. Ilya V. Kublanov ${ }^{7}$ • Olga V. Golyshina ${ }^{2}$ • Graziano Pesole ${ }^{1}$ • \\ Luigi R. Ceci ${ }^{1} \cdot$ Peter N. Golyshin ${ }^{2}$
}

Received: 13 March 2015 / Revised: 12 June 2015 / Accepted: 20 July 2015 / Published online: 13 August 2015

(C) The Author(s) 2015. This article is published with open access at Springerlink.com

\begin{abstract}
A metagenomic fosmid expression library established from environmental DNA (eDNA) from the shallow hot vent sediment sample collected from the Levante Bay, Vulcano Island (Aeolian archipelago) was established in Escherichia coli. Using activity-based screening assays, we have assessed 9600 fosmid clones corresponding to approximately $350 \mathrm{Mbp}$ of the cloned eDNA, for the lipases/ester-
\end{abstract}

Antonio Placido and Tran Hai contributed equally to this work.

Electronic supplementary material The online version of this article (doi:10.1007/s00253-015-6873-x) contains supplementary material, which is available to authorized users.

Tran Hai

dr_tranhai@yahoo.de

1 Institute of Biomembranes and Bioenergetics (CNR), Via Amendola 165/A, 70126 Bari, Italy

2 School of Biological Sciences, Bangor University, Bangor, Gwynedd LL57 2UW, UK

3 Institute of Catalysis, Consejo Superior de Investigaciones Científicas (CSIC), 28049 Madrid, Spain

4 Department of Chemical Engineering and Applied Chemistry, University of Toronto, Toronto, Ontario M5S 3E5, Canada

5 Immanuel Kant Baltic Federal University, 236040 Kaliningrad, Russia

6 Institute for Coastal Marine Environment CNR, 98122 Messina, Italy

7 S.N. Winogradsky Institute of Microbiology, Russian Academy of Sciences, 117312 Moscow, Russia ases/lactamases, haloalkane and haloacid dehalogenases, and glycoside hydrolases. Thirty-four positive fosmid clones were selected from the total of 120 positive hits and sequenced to yield ca. $1360 \mathrm{kbp}$ of high-quality assemblies. Fosmid inserts were attributed to the members of ten bacterial phyla, including Proteobacteria, Bacteroidetes, Acidobateria, Firmicutes, Verrucomicrobia, Chloroflexi, Spirochaetes, Thermotogae, Armatimonadetes, and Planctomycetes. Of ca. 200 proteins with high biotechnological potential identified therein, we have characterized in detail three distinct $\alpha / \beta$-hydrolases (LIPESV12_9, LIPESV12_24, LIPESV12_26) and one new $\alpha$-arabinopyranosidase (GLV12_5). All LIPESV12 enzymes revealed distinct substrate specificities tested against 43 structurally diverse esters and $4 p$-nitrophenol carboxyl esters. Of 16 different glycosides tested, the GLV12_5 hydrolysed only $p$-nitrophenol- $\alpha$-(L)-arabinopyranose with a high specific activity of about $2.7 \mathrm{kU} / \mathrm{mg}$ protein. Most of the $\alpha / \beta$-hydrolases were thermophilic and revealed a high tolerance to, and high activities in the presence of, numerous heavy metal ions. Among them, the LIPESV12_24 was the best temperatureadapted, retaining its activity after $40 \mathrm{~min}$ of incubation at $90{ }^{\circ} \mathrm{C}$. Furthermore, enzymes were active in organic solvents (e.g., $>30 \%$ methanol). Both LIPESV12_24 and LIPESV12_26 had the GXSXG pentapeptides and the catalytic triads Ser-Asp-His typical to the representatives of carboxylesterases of EC 3.1.1.1.

Keywords Vulcano Island · Fosmids · Metagenomic library · Screening $\cdot$ Hydrolase $\cdot$ Lipase $\cdot$ Esterase $\cdot$

Arabinopyranosidase 


\section{Introduction}

The genomic and metabolic diversity of prokaryotic domains of life is an extraordinary source for the development of innovative bio-based products of a high application value (Erickson et al. 2012; Buschke et al. 2013; Cragg and Newman 2013; He et al. 2014; Yu 2014). Marine environments contain an exceptional biodiversity generated and supported by a diversified range of special substrates and extreme conditions, such as high and low temperatures, extreme $\mathrm{pH}$ values, elevated salinities, pressure, and even irradiation. The microbes capable of growth under such extreme physico-chemical and nutritional conditions, the extremophiles, are of a special interest for biotechnology (Glöckner and Joint 2010; Zhang and Kim 2010; Levin and Sibuet 2012). Among extreme marine habitats, the hydrothermal vents outflowing in volcanic areas are inhabited by thermophilic and hyperthermophilic microorganisms (Zusuki et al. 2004). The latter represent a source of novel thermoresistant enzymes with many outstanding properties (Sellek and Chaudhuri 1999; Bruins et al. 2001; Atomi 2005; Kubalov et al. 2009; Wemheuer et al. 2013). The enzymes from extremophilic microorganisms, the extremozymes, become increasingly attractive for modern biotechnology, especially in bio-conversion of waste and renewable substrates for producing biochemicals, and alternative energy (Nogi and Kato 1999; Ferrer et al. 2005; Poli et al. 2010; Blunt et al. 2014; Elleuche et al. 2014; López-López et al., 2014; Grawe et al. 2015). Since extremozymes also exhibit high resistances to solvents, detergents, and high pressure (Alcaide et al. 2014), they became the catalysts of choice in different industrial bio-processes (Egorova and Antranikian 2005). In particular, the hydrolytic enzymes such as carboxylesterases (EC 3.1.1.1), lipases (EC 3.1.1.3), and cellulases (EC 3.2.1.4) are attractive biocatalysts for a number of commercial applications in food, laundry, pharmaceutical, and other chemical industries (Bornscheuer 2002; Frazzetto 2003, Panda and Gowrishankar 2005; Kennedy et al. 2011).

The Levante Bay is situated on the northeastern side of the Vulcano Island and has an active hot gas vent field at a depth of less than $1 \mathrm{~m}$ (Frazzetta et al. 1984). The above sampling site selection therefore fulfils the following important criteria: physical and chemical stability, salinity, elevated temperature, and variety of electron donors and acceptors, determining diverse microbial metabolisms, which makes it a valuable site for metagenomic enzyme study. Moreover, it was shown earlier that some sites of the Vulcano Island hosted dozens of new genera of cultured bacteria and archaea (White et al. 2008). In this work, we report the results of our initial activity-based survey of the metagenomic expression library generated from the environmental DNA (eDNA) extracted from the above site. We characterized three carboxyesterases and one glycosyl hydrolase with respect to their substrate specificities and biochemical properties, and presented the details on the two novel thermostable and solvent-resistant carboxylesterases (E.C. 3.1.1.1) from the family $\alpha / \beta$-hydrolase- 6 , which also exhibited a robust activity in buffers containing polar organic solvents and metal ions.

\section{Materials and methods}

\section{Site description and sample collection}

The sediments (each of approx. $300 \mathrm{~g}$ wet weight) were collected at the Levante Bay (Vulcano Island, Aeolian archipelago) $\left(38.4162^{\circ} \mathrm{N}, 14.9603^{\circ} \mathrm{E}\right)$ on October 2, 2012, at the depth of water column of about $0.5-2.0 \mathrm{~m}$; the sediment depth was $0-0.3 \mathrm{~m}$.

\section{Bacterial strains and vectors used in this work}

The Escherichia coli strains applied in this research for the construction of a metagenomic fosmid library as well as for cloning and protein expression, and the primer pairs for cloning the most significant hydrolases are shown in Table 1. Luria-Bertani (LB) liquid broth and LB agar media were used to grow E. coli. Antibiotics applied in media were chloramphenicol $(12.5 \mathrm{mg} / \mathrm{l})$ for fosmids and ampicillin $(100 \mathrm{mg} / \mathrm{l})$ for pET-46c Ek/LIC expression vectors cloned in E. coli.

\section{Extraction of eDNA from the Vulcano sediment samples and generation of the fosmid library}

Extraction of eDNA from $10 \mathrm{~g}$ of the sediments was done using the protocol of Meta-G-Nome DNA Isolation Kit (Epicentre Biotechnologies; WI, USA). The quality and sizes of the extracted DNA were evaluated using agarose electrophoresis, and the DNA concentration was estimated with Quant-iT dsDNA Assay Kit (Invitrogen). DNA fragments of $30-40 \mathrm{~kb}$ after the end repair were recovered using electrophoresis in a low-melting-point agarose gel, extracted using the Gelase (Epicentre Biotechnologies; WI, USA) and ligated to the linearized fosmid vector pCC2FOS according to the protocol of the manufacturer (CopyControl ${ }^{\mathrm{TM}}$ Fosmid Library Production Kit, Epicentre). After the in vitro packaging into the phage lambda (MaxPlax ${ }^{\mathrm{TM}}$ Lambda Packaging Extract, Epicentre), the transfected phage T1-resistant EPI300TM-T1 ${ }^{\mathrm{R}}$ $E$. coli cells were spread on LB agar medium containing $12.5 \mu \mathrm{g} / \mathrm{ml}$ chloramphenicol and incubated at $37^{\circ} \mathrm{C}$ overnight to determine the titre of the phage particles. The resulting library dubbed V12 had a total titre of 40,000 clones. The ten randomly chosen fosmid clones were analysed using NotI and/or BamHI endonuclease digestion of purified fosmids to evaluate the size of the cloned eDNA. For longer-term storage, the whole library was plated onto the same solid medium, and after an overnight growth, colonies were collected from 
Table 1 Bacterial strains and vectors used for this research

\begin{tabular}{|c|c|c|}
\hline Strain, vector, or primers & Relevant markers and characteristics & Reference \\
\hline Escherichia coli EPI300 & $\begin{array}{l}\text { The cells contain an inducible mutant trfA and tonA genotype: } \\
\text { F-mcrA } \Delta(\text { mrr-hsdRMS-mcrBC) } \varphi 80 \text { dlacZ } \Delta M 15 \Delta \text { lacX74 recAl } \\
\text { endAl araD139 } \Delta \text { (ara, leu } 7697 \text { galU galK } \Gamma \text { - rpsL nupG trfA tonA }\end{array}$ & Epicentre, Madison, WI, USA \\
\hline E. coli NovaBlue & $\begin{array}{l}\text { endA1 hsdR17 }\left(\mathrm{r}_{\mathrm{K} 12}-\mathrm{m}_{\mathrm{K} 12}{ }^{+}\right) \text {supE44 thi-1 recA1 gyrA96 relA1 lac F } \\
\quad\left[\operatorname{proA}^{+} \mathrm{B}^{+} \text {lacl }^{\mathrm{Q} Z} \mathrm{Z} \Delta \mathrm{M} 15: \mathrm{Tn} 10\right]\left(\mathrm{Tet}^{\mathrm{R}}\right)\end{array}$ & Novagen, Merck, Germany \\
\hline E. coli $\mathrm{BL} 21(\mathrm{DE} 3)$ & $\begin{array}{l}\text { fhuA2 [lon] ompT gal }(\lambda \text { DE3) }[\mathrm{dcm}] \Delta \text { hsdS } \lambda \text { DE3 }=\lambda \text { sBamHIo } \\
\quad \Delta E c o R I-B \text { int::(lacI::PlacUV5::T7 genel) i21 } \Delta \text { nin } 5\end{array}$ & Biolab, CA, USA \\
\hline pCC2FOS-vector & A copy control fosmid kit (Cat. No. CCFOS059) & Epicentre, USA \\
\hline pET46c/Lic & $\begin{array}{l}\text { Ligase-independent cloning vector kit Ek/LIC cloning kit of Novagen } \\
\text { (Cat. No. 71335) }\end{array}$ & Novagen, Merck, Germany \\
\hline E. coli NovaBlue & Transformant strain harbouring LIPESV12_24 & This study \\
\hline E. coli $\mathrm{BL} 21(\mathrm{DE} 3)$ & Protein expression strain harbouring LIPESV12_24 & This study \\
\hline E. coli NovaBlue & Transformant strain harbouring LIPESV12_26 & This study \\
\hline E. coli $\mathrm{BL} 21(\mathrm{DE} 3)$ & Protein expression strain harbouring LIPESV12_26 & This study \\
\hline E. coli NovaBlue & Transformant strain harbouring ABO_1197 & This study \\
\hline E. coli $\mathrm{BL} 21(\mathrm{DE} 3)$ & Protein expression strain harbouring ABO_1197 & This study \\
\hline E. coli NovaBlue & Transformant strain harbouring ABO_1251 & This study \\
\hline E. coli $\mathrm{BL} 21(\mathrm{DE} 3)$ & Protein expression strain harbouring ABO_1251 & This study \\
\hline
\end{tabular}

the agar surface by using liquid LB medium containing $20 \%$ $(v / v)$ sterile glycerol and the aliquots were stored at $-80{ }^{\circ} \mathrm{C}$.

\section{Screening the metagenomic library V12}

Single fosmid clones obtained by plating the pooled library from the above step on LB agar were arrayed in 384-microtitre plates containing LB medium supplemented with chloramphenicol. The cells were grown at $37{ }^{\circ} \mathrm{C}$ overnight and then directly used for screening assays. Replica plates were also produced and stored at $-80{ }^{\circ} \mathrm{C}$ in the LB broth with chloramphenicol $(12.5 \mu \mathrm{g} / \mathrm{ml})$ and $20 \%(v / v)$ glycerol for next using.

\section{Agar-based esterase/lipase activity screening}

Every six master 384 -well microtitre plates were printed on the surface of a large $(22.5 \mathrm{~cm} \times 22.5 \mathrm{~cm})$ square Petri dish containing LB medium supplemented with chloramphenicol $(12.5 \mathrm{mg} / \mathrm{l})$, copy control fosmid induction solution (Epicentre Biotechnologies; Madison, USA) (2 ml/1), and 0.5-1.0\% $(v / v)$ tributyrin emulsified with gum arabic $(2: 1, v / v)$ by sonication. The replicated clones were grown for $18-40 \mathrm{~h}$ at $37^{\circ} \mathrm{C}$. The active lipolytic enzymes hydrolysed tributyrin and formed transparent zones around the colonies. The active esterase hits were verified by using Fast Blue RR and $\alpha$-naphthyl acetate solution, as described previously (Khalameyzer et al. 1999).

\section{Screening for cellulase activities}

The cellulolytic active hits were identified by using lowdensity carboxymethyl cellulose (CMC) with a final concentration of $0.5 \%$ weight to volume $(w / v)$. After $48 \mathrm{~h}$ of growth at $37{ }^{\circ} \mathrm{C}$, the colonies were thoroughly removed from the agar plates by small volumes of $0.1 \%(w / v)$ Congo Red (CR) solution in $20 \%(v / v)$ ethanol. Then, the agar plates were submerged in the new CR solution and stained for 20 min with shaking. The unbound $\mathrm{CR}$ was removed from the plates by washing with $1 \mathrm{M} \mathrm{NaCl}$ two times, each for $30 \mathrm{~min}$. The cellulose-active clones formed transparent zones around the colonies. The activity confirmation in selected clones was done in $\varnothing 9$-cm Petri dishes.

\section{Screening for other glycoside hydrolase activities}

The glycosidase activity screening was carried out by using chromogenic glycosides, such as 5-bromo-4-chloro-3indolyl- $\beta$-D-galactopyranoside (X-gal) for betagalactosidases and other substrate-non-specific glycosidases (30 $\mu \mathrm{g} / \mathrm{ml})$, in which the actively expressed enzymes hydrolyse the glycosidic bonds and turned the colourless substrate into insoluble indigo-like blue precipitates. The rescreening was done in mini agar plates $(\varnothing 6 \mathrm{~cm})$ by using the fluorescent aglicon of 4-methylumbelliferyl beta-(D)-glycoside.

\section{Screening for haloalkane dehalogenases and haloacid dehalogenases}

Clones were replicated into 96-well microtitre plates containing per well $200 \mu \mathrm{l}$ of LB broth with chloramphenicol and the induction solution (as above), and grown overnight (18 h) at $37^{\circ} \mathrm{C}$ with shaking at $220 \mathrm{rpm}$. Then, $20 \mu \mathrm{l}$ of reaction cocktail of haloacids and haloalkanoic acids (chloroacetic acid, 
bromoacetic acid, 1,3-dichloropropanol, 1,2dibromopropanol, 3-bromo-2-methylpropionic acid) at a concentration of $0.1 \mathrm{mM}$ each in $10 \mathrm{mM} \mathrm{N}$-(2hydroxyethyl)piperazine- $N N^{\prime}$-(3-propanesulphonic acid) (EPPS) buffer $\mathrm{pH} 8.0$, containing $20 \%(v / v)$ of dimethylsulphoxide, was added. Sealed plates were incubated at $37^{\circ} \mathrm{C}$ with shaking at $180 \mathrm{rpm}$ for further $30 \mathrm{~min}$. Then, $5 \mu \mathrm{l}$ of $0.5 \mathrm{mM}$ phenol red in the EPPS buffer was added to the vials and positive hits were detected by the production of a yellow colour due to the liberation of inorganic haloacids into the medium. The activity was re-confirmed on agar plates. Overnight-grown colonies were covered with a soft $(0.6 \%)$ agar in the EPPS buffer containing the substrate cocktail ( $4 \%$ $w / v)$. After a short incubation $(30 \mathrm{~min})$ at $37{ }^{\circ} \mathrm{C}$, the hits were verified by adding the $\mathrm{pH}$ indicators.

\section{Extraction of fosmid DNA for sequencing}

The fosmid DNA extraction was done by using the LargeConstruct Kit (QIAGEN, Hilden). The host chromosomal DNA contamination in the samples was reduced by using ATP-dependent exonuclease of Epicentre (Cambio Ltd., Cambridge, UK). The purity of the fosmid DNA and the assessment of the approximate size of the cloned fragment were done by NotI and/or BamHI endonuclease digestion and fragments' visualization after agarose gel electrophoresis.

\section{DNA sequencing, insert assembly, and annotation}

The Sanger reads for terminal nucleotide stretches of each purified fosmid were done by Macrogen Ltd. (Amsterdam, The Netherlands). Then, the pools of the individual fosmids were sequenced using the Illumina MiSeq platform. For the preparation of libraries for next-generation sequencing, we pooled five fosmids in a minicentrifuge tube in equimolar ratios. DNA fragmentation was conducted with Bioruptor UCD-200 sonicator (Diagenode, Belgium) using parameters adjusted to obtain $800-1000$-bp fragments. The fragment libraries have been prepared by NebNext Ultra DNA Library preparation kit (New England Biolabs, USA) according to the manufacturer's instructions. Then, the multiplexed libraries were sequenced on MiSeq Sequencing System (Illumina, San Diego, USA) with a $2 \times 150$-bp sequencing kit.

Obtained paired end reads were subjected to stringent quality filtering and trimming by CLC Genomics Workbench 6.5 (CLCbio, Denmark), and removal of reads associated to E. coli $\mathrm{K} 12$ genomic DNA and pCC2FOS vector DNA was performed by the Deconseq software package (Schmieder and Edwards 2011). Reads remaining after the filtering step were used for de novo assembly with a CLC assembler and further scaffolding by SSPACE software (Boetzer et al. 2011) and in silico filling of gaps using GapFiller (Boetzer and Pirovano, 2012). Assembled contigs were checked for quality using mapping of all the reads back to contigs and analysis of uniformity of coverage and distribution of broken read pairs along the contig. Completeness of insert sequences of a contig was confirmed by occurrence of pCC2FOS polylinker sequences. To identify fosmids in the pool, we initially performed Sanger sequencing of the termini of each fosmid using standard pCC2FOS sequencing primers (Epicentre, UK) and aligned resulting reads with all contigs obtained for a pool using a local BLAST algorithm.

Gene prediction and primary functional annotation were done using the RAST annotation pipeline (Aziz et al. 2008; Overbeek et al. 2014) and the MetaGeneMark annotation software (http://opal.biology.gatech.edu). The taxonomy of the hosts was analysed also by using BLAST2GO software (Conesa et al. 2005). Amino acid alignment was done by using ClustalW2 as well as HMMER tools (http://hmmer. janelia.org, Finn et al. 2011), and the phyla and orders were predicted using an $\mathrm{E}$ value $<\mathrm{e}^{-20}$ as a cut-off. The multiple protein alignments were conducted also by using the MUSCLE application (Edgar 2004) and ClustalW in BioEdit software (Hall 1999) with default settings. The neighbourjoining and maximum likelihood trees were constructed in MEGA v.6.06 (Tamura et al. 2013) using the settings for the Poisson model and homogenous patterning between lineages. The bootstrapping was performed with 1000 replicates, if not indicated otherwise. The 3D structure prediction for LIPESV12_24 and LIPESV12_26 was analysed using Phyr_2 (http://www.sbg.bio.ic.ac.uk/phyre2) and Pymol (www.pymol.org).

\section{Gene cloning and protein purification}

For characterization of enzymes predicted in the positive fosmid clones, we have chosen three carboxylesterases and one glycosyl hydrolase. Their genes were amplified by PCR using MyTaq ${ }^{\mathrm{TM}}$ Red DNA polymerase (Bioline, London, UK) and the custom oligonucleotide primer pairs: LIPESV12-9-FP and RP; LIPESV12_24-FP and RP; LIPESV12_26-FP and RP; ABO_1197-FP and RP; ABO_1251-FP and RP; and GLV12_5-FP and RP. The oligonucleotide sequences with pET-46c Ek/LIC adaptors are given in Table 2. The corresponding positive fosmid was used as a template to amplify the target genes.

\section{Cloning and expression of selected genes in $E$. coli}

The PCR primer pairs (Table 2) with the nucleotide adapters used in this research were designed following a ligationindependent cloning protocol of Novagen (Darmstadt, Germany). The reactions were done in a Techne TC-5000 cycler (CA, USA) using the following programme: 1 cycle of $95^{\circ} \mathrm{C} / 3$ min following 35 cycles of $95^{\circ} \mathrm{C}$ for $30 \mathrm{~s}, 55^{\circ} \mathrm{C}$ for $30 \mathrm{~s}$, and $72^{\circ} \mathrm{C}$ for $1 \mathrm{~min}$ per 1000 nucleotides, followed by 
Table 2 Primers were designed and used in this study

\begin{tabular}{ll} 
Primers $^{\mathrm{a}}$ & Oligosequences of direction 5' to 3' \\
\hline LIPESV12-9-FP & GACGACGACAAGATGCGGTACCTGAATGAAGTG \\
LIPESV12-9-RP & GAGGAGAAGCCCGGTTATTTAAAAAAAGACTTC \\
LIPESV12_24-FP & GACGACGACAAGATGACCATCACCACCAGCGAAAG \\
LIPESV12_24-RP & GAGGAGAAGCCCGGTTAACTTGAGGCGGGCGGGG \\
LIPESV12_26-FP & GACGACGACAAGATGCCGCACCCCACCATCCAGAC \\
LIPESV12_26-RP & GAGGAGAAGCCCGGTTACGATTTGCTGGAAGAGAC \\
ABO_1197-FP & GACGACGACAAGATGCAACTGAAACACCTTTTTC \\
ABO_1197-RP & GAGGAGAAGCCCGGTTAGGGGCGAACTTCGCGCCAGC \\
ABO_1251-FP & GACGACGACAAGATGATGACAGCAATAATTCGTC \\
ABO_1251-RP & GAGGAGAAGCCCGGTTAAACCACCGGGATGATGTC \\
GLV12_5-FP & GACGACGACAAGATGCCTGTGAAGAACGTCCTTC \\
GLV12_5-RP & GAGGAGAAGCCCGGTTACCGGAAATCCAGTTCGTAC \\
\hline a The oligomers were designed with adapter after Ek/LIC Cloning Kit instruction of Novagen (Merck, Germany) \\
and were purchased from Eurofins (Eurofins Genomics, Ebersberg, Germany)
\end{tabular}

one extension at $72{ }^{\circ} \mathrm{C}$ for $5 \mathrm{~min}$. The purified PCR products were then purified, treated with an endonuclease, annealed to His-tag harbouring the pET-46c Ek/LIC vector, and transformed into $E$. coli NovaBlue according to the protocol of the manufacturer (Novagen, Darmstadt, Germany). The DNA inserts in the resulting plasmids were verified by sequencing services of Macrogen Ltd. (Amsterdam, The Netherlands).

The expression of hydrolases in E. coli BL-21 (DE3) was carried out in two steps: at first, the inocula were grown in LB medium supplemented with $100 \mu \mathrm{g} / \mathrm{l}$ ampicillin in an incubator at $37^{\circ} \mathrm{C}$, with shaking at $220 \mathrm{rpm}$ to the OD600 of 0.8-0.9. The cultures were then transferred to an incubator at $18^{\circ} \mathrm{C}$ and induced by adding isopropyl- $\beta$-D-galactopyranoside (IPTG) at a final concentration of $0.5 \mathrm{mM}$. The cells were grown overnight under the above conditions and then harvested by centrifugation $\left(5000 \mathrm{~g}\right.$ for $30 \mathrm{~min}$ at $4{ }^{\circ} \mathrm{C}$ ). The recombinant proteins were purified by affinity chromatography on Ni-NTA His-Bind columns (Novagen) and gel filtration using 10-kDa cut-off centrifugal filter units (Merck KGaA) according to the protocol of the manufacturers. The size and purities of the histagged protein preparations have been analysed by sodium dodecyl sulphate polyacrylamide gel electrophoresis (SDSPAGE) using $10 \% v / v$ precast gels (Expedeon).

\section{Hydrolytic activity assay}

The general assay methods were reported previously (Gupta et al. 2002). In our study, the hydrolytic activities of the LIPESV12 $\alpha / \beta$-hydrolases were (if not mentioned otherwise) estimated colorimetrically in $500 \mu \mathrm{l}$ of $50 \mathrm{mM}$ potassium phosphate (K,P) buffer ( $\mathrm{pH} 7.0$ ), containing $0.1 \%$ Triton $\mathrm{X}-100$, substrate, and enzyme as described recently (Pérez et al. 2012; Tchigvintsev et al. 2014). Briefly, the substrates para-nitrophenyl ( $p$-NP)-carboxylic acid esters were added from $10 \mathrm{mM}$ stock solution in a buffer containing acetonitrile:dimethyl sulphoxide (1:1 of $v / v)$ to get a final concentration of $1 \mathrm{mM}$. The enzyme $(1.8 \mu \mathrm{g})$ for reaction (native) or for reference (overheated) was added from stock solution after $1 \mathrm{~min}$ of preincubation of the reaction vials at an appropriate temperature as requested. The reactions (if not mentioned otherwise) were incubated in an Eppendorf thermomixer comfort with a mixing frequency of $500 \mathrm{rpm}$. After $10 \mathrm{~min}$ of incubation, if not indicated otherwise, the reactions were stopped by adding $500 \mu$ l of cold K,P-buffer (50 mM, pH 8.0) containing 10 mM EDTA (pH 8.0). The stopping solution did change the $\mathrm{pH}$ in the reaction vial, at the values tested, to slightly alkaline $(\mathrm{pH} 7.2-8.0)$ for maintaining the released $p$-NP in the phenolate form. The absorption was measured on a spectrophotometer of model JENWAY 6300 (Progen, UK), if not described otherwise, at $410 \mathrm{~nm}$ in the temperature range from 10 to $50{ }^{\circ} \mathrm{C}$ or at $380 \mathrm{~nm}\left(55-80^{\circ} \mathrm{C}\right)$ with respect to hypsochromic shift and blunting peak formation of the overheated $p$-NP. The blank samples with all reaction components and with inactivated enzymes were run in parallel. Before reading the absorbance of each enzyme reaction, the absorbance of the blank was set to 0 , in order to omit the background rates caused by random hydrolysis of the $p$-NP-ester substrates during incubation. Then, the concentration of enzyme products was calculated using simple linear regression equation (Microsoft Excel) given on each individual standard curve of $p$-NP (Sigma-Aldrich, UK, PA grade) for each test series. The substrate profiling assays for other hydrolytic activities against esters other than $p$-NP esters were tested in 96-well plates using 43 structurally diverse esters (read at $540 \mathrm{~nm}$ ) as described recently (Alcaide et al. 2015). Briefly, assay reactions (in triplicate) were conducted at $30{ }^{\circ} \mathrm{C}$ measuring the absorbance during a total time of 30 min each $1 \mathrm{~min}$ in a Synergy HT Multi-Mode Microplate Reader (BioTek, Bad Friedrichshall, Germany). Reaction mixture started by adding $1.3 \mu \mathrm{g}$ protein stock solution to an 
assay mixture containing $4 \mu \mathrm{l}$ of ester stock solution $(200 \mathrm{mg} / \mathrm{ml}$ in acetonitrile), to a final concentration of $4 \mathrm{mg} / \mathrm{ml}$, in $196 \mu \mathrm{l}$ of $5 \mathrm{mM}$ EPPS buffer, $\mathrm{pH} 8.0$, containing $0.45 \mathrm{mM}$ phenol red $\left(\varepsilon\right.$ at $\left.540 \mathrm{~nm}=8500 \mathrm{M}^{-1} \mathrm{~cm}^{-1}\right)$.

Glycosidase activity for GLV12_5 was assayed using 15 different $p$-NP sugar derivatives that included $\alpha / \beta$-glucose, $\alpha / \beta$-galactose, $\alpha$-maltose, $\beta$-cellobiose, $\alpha / \beta$ arabinopyranose, $\alpha / \beta$-arabinofuranose, $\alpha / \beta$-xylose, $\beta$-mannose, $\alpha$-rhamnose, and $\alpha$-fucose in 96 -well plates as previously described (Alcaide et al. 2015). Briefly, assay reactions were conducted at $30^{\circ} \mathrm{C}$ by adding $1 \mu \mathrm{g}$ enzyme and $10 \mu \mathrm{l}$ of substrate from a stock solution $(10 \mathrm{mg} / \mathrm{ml}$ freshly prepared in $45 \mathrm{mM}$ 4-(2-hydroxyethyl)-1-piperazineethanesulphonic acid (HEPES) buffer, $\mathrm{pH} 7.0$ ) in $190 \mu \mathrm{l}$ of $45 \mathrm{mM}$ HEPES buffer, $\mathrm{pH} 7.0$, to get a final volume of each vial of $200 \mu \mathrm{l}$, and the final substrate concentration was $500 \mu \mathrm{g} / \mathrm{ml}$. Absorbance was read in triplicate assays at $405 \mathrm{~nm}$ in a Synergy HT MultiMode Microplate Reader (BioTek, Bad Friedrichshall, Germany) to follow the extent of the hydrolysis $\left(\varepsilon_{p \text {-NP }}\right.$ at $405 \mathrm{~nm}=16,325 \mathrm{M}^{-1} \mathrm{~cm}^{-1}$ ) during $30 \mathrm{~min}$. All values were corrected with non-enzymatic transformation as blank.

The $p$-NP-butyrate (C4) is visually more stable relating to diverse temperatures and $\mathrm{pH}$ values of buffers as well as in the presence of metal ions or organic solvents in comparison to $p$ NP-acetate (C2). Therefore, we used $p$-NP-C4 in this study as a universal substrate for biochemical enzyme characterization. Thermal stability was determined after incubation of the enzyme for 5, 20, 30, and $40 \mathrm{~min}$ at temperatures 55, 60, 70, 80, and $90{ }^{\circ} \mathrm{C}$ with shaking at $500 \mathrm{rpm}$. The enzyme solutions were cooled down on ice, and the activity was estimated following the standard protocol as described in the "Materials and methods". The half-life for LIPESV12 24 was measured by incubating the enzyme at $55^{\circ} \mathrm{C}$, and samples were taken after $0.5,1,2,3,4$, and $24 \mathrm{~h}$. Then, the retaining activities were assayed using $1 \mathrm{mM} p$-NP-C4 as substrate.

The optimal $\mathrm{pH}$ for the enzyme activity was determined in the range of $\mathrm{pH} 5.5-9.0$ at $30^{\circ} \mathrm{C}$ in $20 \mathrm{mM}$ of different buffer systems including sodium citrate $(\mathrm{pH} 5.5)$, potassium phosphate ( $\mathrm{pH} 7.0)$, HEPES ( $\mathrm{pH} 7.5)$, Tris- $\mathrm{HCl}(\mathrm{pH} 8.0$ ), and Tris$\mathrm{HCl}(\mathrm{pH} 9.0$ ), with incubation time of $10 \mathrm{~min}$. The substrate for the assays was $1 \mathrm{mM} p$-NP-C4. The reference variant with inactivated enzymes was applied and used also as blank for absorbance reading. The enzyme reactions were stopped by adding the buffer with higher $\mathrm{pH}$ values for maintaining $p$-NP released in a phenolate form as described above. The concentration of released $p$-NP was determined using an individual standard curve for each experiment as described above.

The effects of different bivalent cations $\left(\mathrm{Cu}^{2+}, \mathrm{Mn}^{2+}\right.$, $\mathrm{Mg}^{2+}, \mathrm{Zn}^{2+}, \mathrm{Co}^{2+}$, and $\mathrm{Ca}^{2+}$ ) each at $1 \mathrm{mM}$, and organic solvents (acetonitrile, methanol, ethanol, isopropanol, 1,2propanediol, and dibutyl phosphate) in a range of concentrations from 5 to $80 \%(v / v)$ on the activity of the LIPESV12 proteins were also evaluated. All the enzyme tests were performed in triplicate at $30^{\circ} \mathrm{C} / 10 \mathrm{~min}$ using $1 \mathrm{mM} p$-NP$\mathrm{C} 4$ as substrate as mentioned above. The average values with standard deviations were applied.

In all cases, the specific activity of enzymes were given in units per milligram of protein, where one unit (U) of activity was defined as the amount of enzyme required to transform $1 \mu \mathrm{mol}$ of substrate in $1 \mathrm{~min}$ under the assay conditions.

\section{Chemicals}

All chemicals used for enzymatic tests were of PA grade, which have been purchased from Sigma-Aldrich Chemical Co. (St. Louis, MO, USA). The kits applied in this study with individual manufacturers have been noticed in the text.

\section{Accession numbers}

The genes cloned in this study for LIPESV12_9, LIPESV12_24, LIPESTV12_26, and GLV12_5 are deposited in the EMBL/GenBank/DDBJ databases under the accession numbers KR919661, KP861227, KP861228, and KR919662, respectively.

\section{Results}

\section{V12 fosmid library generation and screening the industrial relevant enzymes}

As estimated by the library titration and insert restriction analysis of a set of randomly chosen fosmids, the V12 library contained approx. 40,000 clones with cloned DNA fragments between 30 and $40 \mathrm{kbp}$ in size, which implies the V12 library size corresponds to approximately $1.4 \mathrm{Gbp}$ of the cloned eDNA.

Using agar plates containing one of the following substrates, tributyrin, carboxylmethylcellulose, mixture of haloacids and haloalkanoic acids, or X-gal, we screened 9600 clones and identified 120 positive hits. Among them, 50 hits were positive for the hydrolysis of tributyrin showing carboxylesterase/lipase activities, 36 hits for the hydrolysis of $\mathrm{X}$-gal showing $\beta$-glycosyl hydrolase (galactosidase) activities, 10 hits for the hydrolysis of carboxylmethylcellulose (CMC) showing cellulase activity, and 24 hits revealed dehalogenase activities.

Among the 120 hits, a set of 40 most active clones, which revealed larger halo zones on agar plates containing tributyrin (lipases/esterases (LIPES) relating hits) and cellulases (CMCases) or strong chromogenic signals of glycosidase (GLY) and dehalogenases (HAD), were chosen for further analysis (some representative hits are presented on Fig. 1). The termini of purified fosmids were Sanger-sequenced by using standard $\mathrm{pCC} 2$-FOS forward and reverse primers. The 
Sanger read analysis allowed us to filter redundant hits or those with high similarity with already-characterized proteins or with absolute nucleotide identities with known genomes. In that manner, six hits including four HADs, one LIPES, and one $\mathrm{GH}$ were discarded from further analysis.

\section{DNA sequence analysis of hits}

The total size of the eDNA corresponding to the selected 34 hits was about $1360 \mathrm{kbp}$. By the annotation of the sequences, we have identified about 200 open reading frames (ORFs) encoding relevant hydrolytic enzymes of interest. In fact, most of them showed only partial domain similarities to hydrolases from non-redundant databases. We have chosen 60 ORFs encoding esterases/lipases (26 hits) (EC 3.1.1.-) and $\beta$ lactamases (9 hits) (EC 3.5.2.-), and 5 ORFs encoding haloalkane and haloacid dehalogenases (HAD) (EC 3.8.1.-), $\mathrm{C}-\mathrm{N}$ hydrolases (5 hits) (EC 3.5.-.), and glycosyl hydrolases (EC 3.2.1.-) (15 hits) (Supplementary Table S1). Among the annotated ORFs, the $\beta$-lactamases, as well as some thioesterases and the $\mathrm{C}-\mathrm{N}$ hydrolase genes, were deduced from the nucleotide sequences of the hits exhibiting tributyrin hydrolytic activities as described in the "Materials and methods" section.

\section{Phylogenetic analysis of hydrolytic enzymes}

From BLAST analysis carried out using the selected 60 ORFs as query sequences, we have identified the proteins with the highest identity and putative producing organisms. The 60 hydrolases were affiliated within a broad spectrum of bacterial phyla to include Proteobacteria (E value ranging from $1.00 \mathrm{e}^{-35}$ to 0$)$, Bacteroidetes $\left(5.00 \mathrm{e}^{-48}\right.$ to 0$)$, Acidobacteria $\left(1.00 \mathrm{e}^{-128}-0\right)$, Firmicutes $\left(2.00 \mathrm{e}^{-22}-5.00 \mathrm{e}^{-127}\right)$, Verrucomicrobia $\left(5.00 \mathrm{e}^{-22}-9.00 \mathrm{e}^{-114}\right)$, Chloroflexi $(0)$, Spirochaetes $\left(1.00 \mathrm{e}^{-99}\right)$, Thermotogae $\left(1.00 \mathrm{e}^{-164}\right)$, Armatimonadetes $\left(1.00 \mathrm{e}^{-50}\right)$, and Planctomycetes $\left(1.00 \mathrm{e}^{-156}\right)$. Among only the lipolytic and dehalogenase hits, 18 associated to known and three to unknown bacterial orders. For more details about the nearest microbial taxa from which cloned DNA fragments were derived, see Tables S1 and S2 in the Electronic supplementary material (ESM). The protein families within each hydrolase group, namely, the LIPESV12_series for lipases/esterases (EC 3.1.1.-), the BLAV12_series for $\beta$-lactamases (EC 3.5.2.-), the CNV12_series for nitrilases and other $\mathrm{C}-\mathrm{N}$ hydrolases (EC 3.5.--), the HADV12 proteins of haloalkane and haloacid dehalogenases (EC 3.8.1.-), and the GLV12 series for glycosyl hydrolases (EC 3.2.1.-), have been established using interactive sequence similarity searching and HMMER software and is presented in Supplementary Table 2. The clan-specific phylogenetic positions of the lipases/esterases (LIPESV12 ), 9 beta-lactamases (BLAV12_), and 5 C-N hydrolases (C-
NV12_), in lipolytic positive hits have been also highlighted in Figs. S1, S2, and S3 of the ESM, respectively. The relationship between five putative HADV12_proteins and their nearest counterparts is presented in Fig. S4. As the HADV12_ 3 and HADV12_ 4 were related to $\alpha / \beta$-hydrolase superfamily including trehalose phosphatases, the other HADV12 proteins clustered nearly to their counterparts from Desulfarculus baarsii and Microbulbifer agariliticus (Fig. S4). The phylogenetic analysis for 15 GLV12 proteins is also illustrated in Supplementary Fig. S5. The phylogenetic position of GLV12 5 enzyme, one of the glycosyl hydrolases identified with the largest halo zone on $\mathrm{CMC}$ (Fig. 1) with 37 other closely clustered proteins. As a result of the phylogenetic analysis, we have chosen a set of significant new hydrolases, particularly three LIPESV12 (Fig. 2) and one GLV12 enzymes, for further biochemical characterization.

\section{Biochemical characterization of His-tagged proteins}

\section{Substrate specificity of LIPESV12_enzymes}

After verifying the nucleotide sequences by the Sanger readers, we purified three 6 His-tagged LIPESV12 proteins (LIPESV12-9, LIPESV12_24, LIPESV12_26) and one glycosyl hydrolase (GLV12_5) to homogeneity using Ni-NTA affinity chromatography and ultrafiltration with $10 \mathrm{kDa}$ cutoff. The relative molecular masses of the purified protein preparations were confirmed by SDS-PAGE and are illustrated in Fig. S6. For the biochemical characterization, we applied different $p$-NP esters such as $p$-NP-C2, $p$-NP-C4, $p$-NP-laurate (C12), and $p$-NP-palmitate (C16). The standard enzyme tests have been done as described in the "Materials and methods". As references, we have chosen two carboxyesterases, ABO_1177 and ABO_1521, which were characterized recently (Tchviginsev et al. 2014). All of the LIPESV12 hydrolases under standard assay conditions showed higher activities against the $p$-NP-acetate in comparison to the referent $\mathrm{ABO}$ enzymes, which preferred the $p$-NP-C4 as optimal substrate (Table 3). The hydrolytic activities of LIPESV12 enzymes against long-chain fatty acid $p$-NP-esters were significantly lower, even not detectable for LIPESV12-9 and ABO_1251 even after 50-min incubations. After $50 \mathrm{~min}$ of reaction under the conditions described in the "Materials and methods", the other three, LIPESV12_24, LIPESV12_26, and ABO_1197, were significantly activated also in the hydrolysis of the longchain ester $p$-NP-C16 and released approx. 128.0, 554.0, and $12.0 \mu \mathrm{mol} p$-NP per mg protein, respectively. Further, to study the substrate specificities of the LIPESV12 enzymes with respect to other esters with diverse chain lengths and stereoconfigurations in more detail, we performed the substrate fingerprinting, with the results presented below. 
Fig. 1 Agar-based activity screens of lipolytic enzymes (LIPES), haloalkane dehalogenases $(H A D)$, glycosidases $(G L Y)$, and cellulases (CMC-ase) from the Vulcano fosmid library. The halo zones produced by hits are indicated. Among them, the HAD hits, as mentioned in the "Materials and methods", have been rescreened from microtitre plate-based activity screening

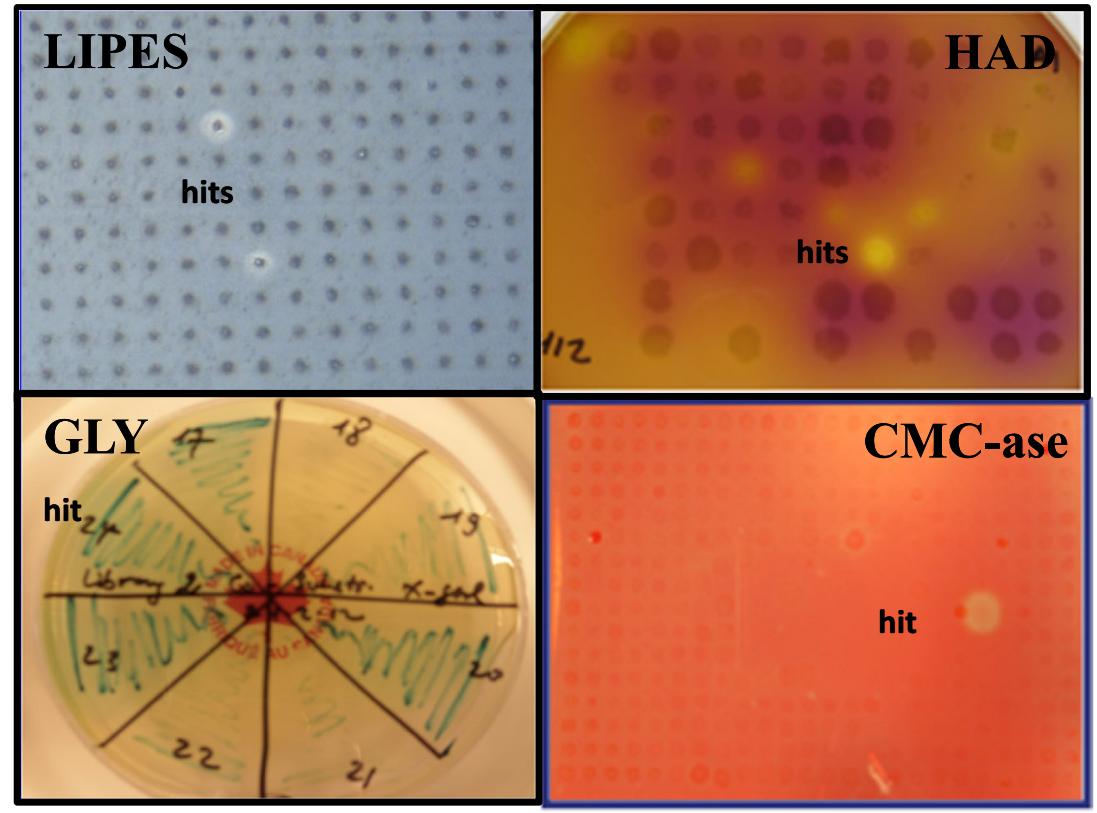

Substrate fingerprinting for the representative LIPESV12 enzymes

A total of 43 ester-like chemicals, other than $p$-NP esters, were used to evaluate the substrate ranges and specific activities $(\mathrm{U} / \mathrm{mg})$ of the three LIPESV12 enzymes at $\mathrm{pH} 8.0$ and at $30{ }^{\circ} \mathrm{C}$ (Fig. 3). Under our assay conditions, the three ester hydrolases hydrolysed short-to-medium-chain-length tri-acyl-glycerides and alkyl esters, but with different ranges of reactivities and orders of preference. Thus, substrate fingerprints revealed that V12_26 (33 positive substrates) exhibited the widest substrate range. Among the three enzymes, V12_26 did show more lipase character, as compared to V12_24 and V12-9; this was demonstrated by its higher capacity to hydrolyse methyl and ethyl hexanoate and octanoate and ethyl decanoate. Halogenated esters were also hydrolysed by V12-9 and V12_26, with the latter being the only one acting against halogenated esters with double bonds (i.e. the alkenyl halogenated ester methyl 2-bromo-2butenoate). Under our assay conditions, all three ester hydrolases were also found to be enantio-selective to different degrees and preferences for at least eight chiral esters, including methyl- $( \pm)$-mandelate, methyl- $( \pm)$-lactate, $( \pm)$ menthylacetate, $( \pm)$-neomenthyl acetate, $( \pm)$-glycidyl 4nitrobenzoate, $( \pm)$-pantolactone, and $( \pm)$-methyl $(S)$-3hydroxybutyrate. Three hydrolases further utilized tri- $O$ acetyl-glucan and two the carbohydrate ester $\alpha$-D-glucose pentaacetate (Fig. 3).
Fig. 2 Neighbour-joining phylogenetic tree of the carboxylesterases LIPESV12-9, LIPESV12_24, and LIPESV12 26 and their closely clustered enzymes. The multiple protein alignment was conducted using the MUSCLE application (Edgar, 2004) and BioEdit software (Hall, 1999) with default settings. The phylogenetic neighbour-joining trees were constructed using MEGA v.6.06 (Tamura et al., 2013) as described in the "Materials and methods" with 100 bootstrap replicates. The scale bar reflects the number of substitutions per position

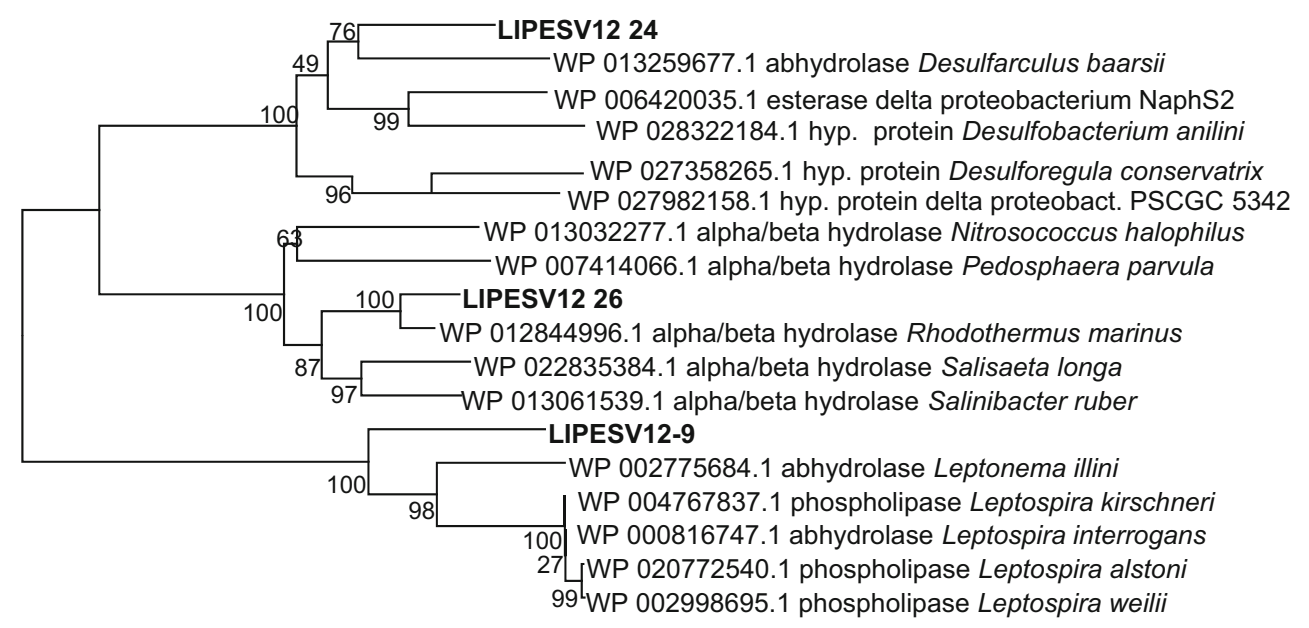

0.2 
Table 3 Substrate specificities, as maximum activities, of the LIPESV12 enzymes in comparison to ABO esterases as references

\begin{tabular}{lllll}
\hline Enzymes/substrate $^{\mathrm{a}}$ & $p$-NP-C2 & $p$-NP-C4 & $p$-NP-C12 ${ }^{\mathrm{b}}$ & $p$-NP-C16 ${ }^{\mathrm{b}}$ \\
\hline LIPESV12_9 & $1145.5 \pm 5.3$ & $334.4 \pm 2.3$ & 0 & 0 \\
LIPESV12_24 & $960.0 \pm 0.5$ & $392.4 \pm 0.6$ & $42.1 \pm 1.2$ & $127.6 \pm 0.6$ \\
LIPESV12_26 & $1053.4 \pm 1.7$ & $806.0 \pm 0.5$ & $314.4 \pm 2.7$ & $553.5 \pm 1.7$ \\
ABO_1197 & $61.3 \pm 6.6$ & $254.7 \pm 1.8$ & $110.4 \pm 7.3$ & $10.2 \pm 12.6$ \\
ABO_1251 & $650.1 \pm 4.5$ & $2100.0 \pm 0.3$ & $57.4 \pm 5.8$ & 0 \\
\hline
\end{tabular}

a Enzyme reactions were carried out as described in the "Materials and methods". The $p$-NP-esters were added from $10 \mathrm{mM}$ stock solution of each to get an end concentration of $1 \mathrm{mM}$. The enzyme assays were set up in triplicate

${ }^{\mathrm{b}}$ The incubation time prolonged to $50 \mathrm{~min}$. The specific activities corresponding to units per milligram of protein with standard deviation ( $\pm \mathrm{SD}$ ) rounded to decimal were given. Protein concentration here and hereafter was estimated by using the standard Bradford reagent kit B-6916 from Sigma

\section{Influence of temperature on stability and activity of LIPESV12_24}

Since the V12 library was generated from a hydrothermal site, we expected LIPESV12 enzymes to exhibit some habitat-specific features. Indeed, not all of the purified enzymes exhibited their thermophilic nature. The maximal activity for activity of LIPESV12_24 was at about 70$80{ }^{\circ} \mathrm{C}(\sim 2800$ and $\sim 3980 \mathrm{U} / \mathrm{mg})$, while LIPESV12_26 reached its maximum activity at $50{ }^{\circ} \mathrm{C}(\sim 1312 \mathrm{U} / \mathrm{mg})$. A summary of the enzyme activity vs temperature profile is shown in Table 4.
The thermostability profiles of LIPESV12 24 are shown in Fig. 4. Noteworthy, the protein manifested a robust residual activity at temperatures ranging from 55 to $90{ }^{\circ} \mathrm{C}$. After 5 and 10 min of incubation at $60-70{ }^{\circ} \mathrm{C}$, the activity was highest and decreased after 40 min of incubation. After a short incubation at $90{ }^{\circ} \mathrm{C}$ (for $5 \mathrm{~min}$ ), the enzyme revealed a lower yet significant activity $(\sim 203 \mathrm{U} / \mathrm{mg})$ pointing at its thermostability. The enzyme became inactive only after a longer incubation time (40 min, $90^{\circ} \mathrm{C}$ ). The half-life of LIPESV12_24 at $55^{\circ} \mathrm{C}$ was also estimated by incubating the enzyme at the temperature and withdrawing aliquots for measurement after $0.5,1,2,3,4$, and $24 \mathrm{~h}$ by the manner described in the "Materials and methods".

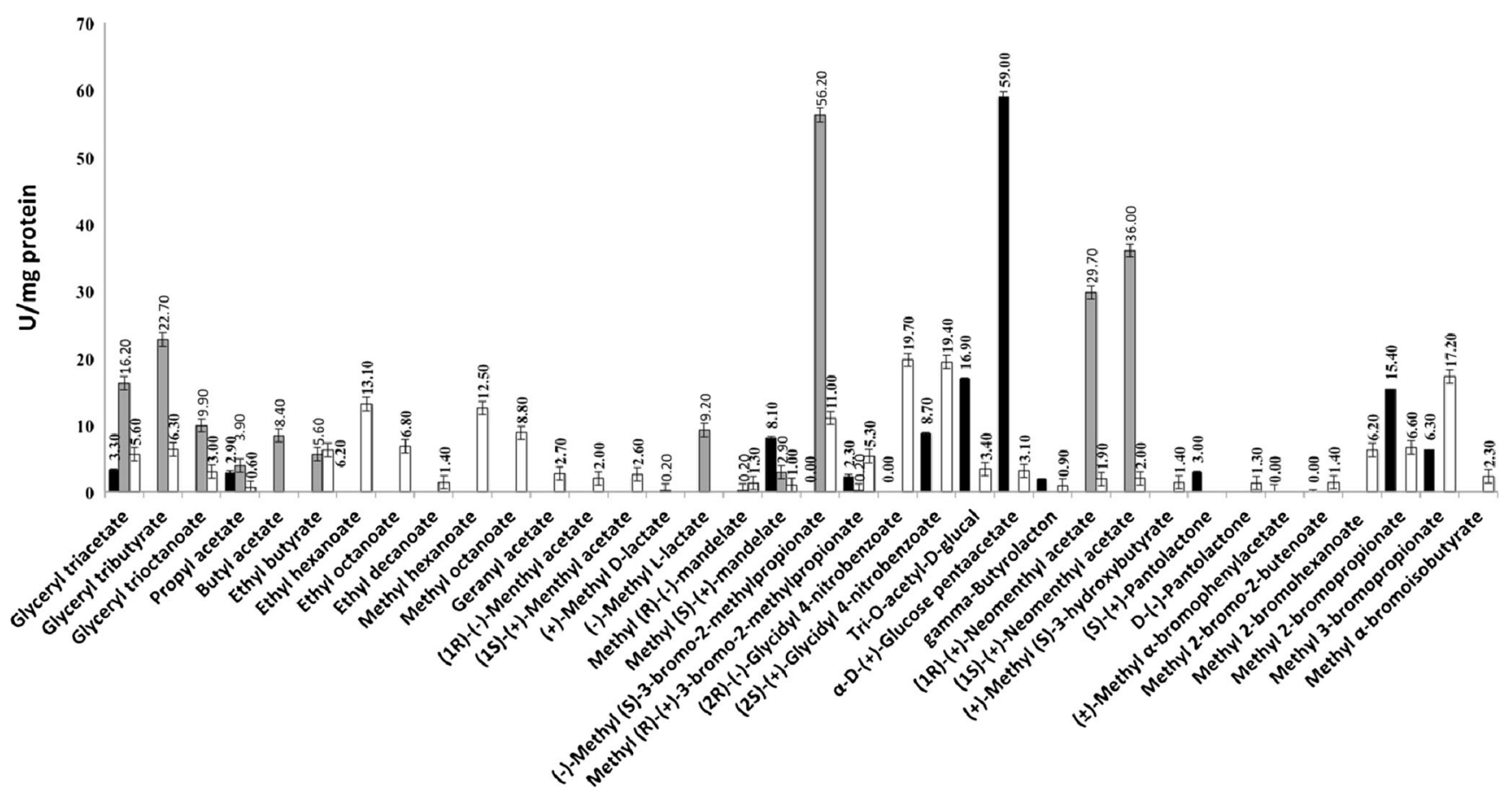

Fig. 3 Substrate profiles of the enzymes with a set of 43 structurally diverse compounds. The specific activities were calculated in triplicate, and average values with standard deviation are shown. The specific esterase/lipase activity of each enzyme (in units/mg protein) against a set of structurally diverse esters was measured after incubation at $30^{\circ} \mathrm{C}$ each minute within 30 min using $1.3 \mu \mathrm{g}$ protein at $\mathrm{pH} 8.0$ in $5 \mathrm{mM}$ EPPS buffer and $4 \mathrm{mg} / \mathrm{ml}$ esters. Of the total 43 compounds, the LIPESV12-9 (solid bar) hydrolysed 17 esters, LIPESV12_24 (grey bar) hydrolysed 15 esters, and LIPESV12_26 (open bar) hydrolysed 33 esters. Some of the activity values (for the cases of ethyl myristate, ethyl benzoate, methyl decanoate, methyl oleate, (R)-(+)-glycidol, (S)-(-)-glycidol, and gamavalerolactone) were negligible and we rounded to 0 
Table 4 Temperature profiles of the V12 $\alpha / \beta$-hydrolases

\begin{tabular}{lll}
\hline & \multicolumn{2}{l}{ Activity $(\%)^{\mathrm{b}}$} \\
\cline { 2 - 3 }$T\left({ }^{\circ} \mathrm{C}\right)^{\mathrm{a}}$ & LIPESV12_24 & LIPESV12_26 \\
\hline 10 & $62.0 \pm 0.5$ & $20.0 \pm 0.5$ \\
20 & $57.0 \pm 0.5$ & $72.0 \pm 0.5$ \\
30 & $100^{\mathrm{c}}$ & $100^{\mathrm{e}}$ \\
37 & $406.0 \pm 0.5$ & $116.0 \pm 1.0$ \\
45 & $451 \pm 0.5$ & $200.0 \pm 1.0$ \\
50 & $517 \pm 0.5$ & $258.0 \pm 0.1$ \\
60 & $100^{\mathrm{d}}$ & $87.0 \pm 0.5^{\mathrm{e}}$ \\
70 & $127.0 \pm 0.5$ & n.d \\
80 & $173.0 \pm 0.5$ & n.d \\
\hline
\end{tabular}

${ }^{\text {a }}$ Enzyme reactions were carried out in triplicate as described in the "Materials and methods" by using $p$-NP-butyrate $(1 \mathrm{mM})$ as substrate

${ }^{\mathrm{b}}$ The measurements of absorbance in the range $10-50{ }^{\circ} \mathrm{C}$ were conducted at the wavelength $410 \mathrm{~nm}$ and at $60-80^{\circ} \mathrm{C}$ - at $380 \mathrm{~nm}$, since the heated $p$-NP revealed a hypsochromic shift as mentioned in the "Materials and methods", and the results with $\pm \mathrm{SD}$ are given, where $100 \%$ activity of ${ }^{\mathrm{c}} 359.0 \pm 0.5,{ }^{\mathrm{d}} 2219.0 \pm 0.5$, and ${ }^{\mathrm{e}} 524 \pm 1.0 \mathrm{U} / \mathrm{mg}$ of proteins

The LIPESV12_24 exhibited about 60 and $40 \%$ its maximum activity (100\% activity corresponded to $610 \pm 0.5 \mathrm{U} / \mathrm{mg}$ ) after 3 and 4 h of incubation. Therefore, its half-life was estimated as being approx. 3-3.5 h.

\section{Effects of $\mathrm{pH}$ and bivalent cations on the activity of enzymes}

We have stopped the enzyme reaction by adding cold alkaline buffer containing EDTA ( $\mathrm{pH}$ 8.0) in order to quench the released $p$-NP into para-nitrophenylate form allowing the colorimetric measurement of the latter at a standard wavelength of $410 \mathrm{~nm}$. These measurements were usefully applied to the $\mathrm{pH}$ activity optimum determination. The $\mathrm{pH}$ range was established at 5.5, 7.0, 7.5, 8.0, and 9.0 by applying citrate, phosphate, HEPES, and Tris-HCl buffers as described in the "Materials and methods". Both the LIPESV12_24 and LIPESV12_26 enzymes altered significantly the activities at acidic $\mathrm{pH}$ values: under slightly acidic conditions ( $\mathrm{pH} 5.5)$, the activity of LIPESV12_24 decreased for about $25 \%$ while the LIPESV12 26 was fully inactivated (remained $<1 \%$ ) in comparison to their activities at $\mathrm{pH}$ 7.0. Both enzymes were particularly active at slightly alkaline $(\mathrm{pH} 8.0)$ and neutral (7.0) $\mathrm{pH}$ values (Fig. 5). The inhibitory effect was observed also for the LIPESV12 26, even at pH 8.0. On the contrary, the LIPESV12 24 retained about $75 \%$ of its activity at $\mathrm{pH} 9.0$ in comparison to its highest values (Fig. 5).

The enzyme kinetics may also be influenced by cofactors such as metal ions. Volcanic environments are characterized by the presence of metal ions at elevated concentrations. We measured the influence of bivalent cations such as $\mathrm{Cu}^{2+}, \mathrm{Co}^{2+}$,

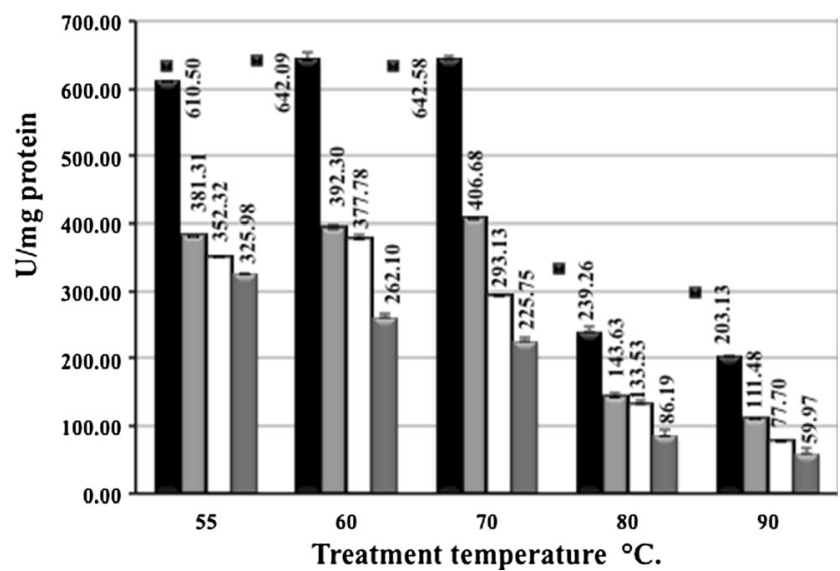

Fig. 4 The thermostability of LIPESV12 24 as a function of incubation time. Since the LIPESV12_24 showed a broad temperature profile and actively hydrolysed the substrates at high temperatures (see Table 3), we checked its thermostability at different incubation times $(5,10,30$, and $40 \mathrm{~min}$ ) and temperatures of $55,60,70,80$, and $90^{\circ} \mathrm{C}$. Residual activity was detected using standard test at $30^{\circ} \mathrm{C}$ as described in the "Materials and methods" section. The activity values given on the top of each column were corresponded also to incubation time: after 5 (solid bar), 20 (lightgrey), 30 (dashed grey), and 40 (open bar) min using $1 \mathrm{mM} p$-NPbutyrate

$\mathrm{Zn}^{2+}, \mathrm{Mn}^{2+}, \mathrm{Mg}^{2+}$, and $\mathrm{Ca}^{2+}$ on the activity of purified LIPESV12_24 during short-term (5 min) and long-term (50 $\mathrm{min}$ ) incubations. After $5 \mathrm{~min}$ of the exposure, the enzyme activity was increased in comparison to the control. Reaction mixtures containing calcium, cobalt, and magnesium salts, each of $1 \mathrm{mM}$, showed almost a twofold increase in the activities as compared to the control (Fig. 6). Long incubation of the enzyme in metal ions in most cases seemed to be not result the increase of enzyme activities. In opposite, some inhibitory effects of copper, zinc, and manganese were observed after a long-term incubation (data not shown). The common effects of the divalent metal ions on the activities of the LIPESV12_24 and LIPESV12_26 enzymes are clearly consistent with the metal-rich conditions in the environment of origin of the source microorganisms.

\section{Effect of organic solvents}

We analysed the activity of both enzymes using $p$-NP-butyrate in the buffer supplemented at different concentrations with 1 , 2-propanediol, isopropanol, ethanol, methanol, acetonitrile, and dibutyl phosphate, the main component of degradation products of tributyl phosphate (TBP), the extractant used in the nuclear fuel reprocessing known as the PUREX process (Table 5). By adding to $5 \%(v / v)$ dibutyl phosphate in the potassium phosphate buffer ( $\mathrm{pH} 7.0)$, the specific activities of both, LIPESV12 24 and LIPESV12 26, enzymes were strongly stimulated ( 2600 and $\sim 955 \mathrm{U} / \mathrm{mg}$, respectively). Interestingly, both LIPESV12_enzymes were activated by acetonitrile with a final concentration of $30 \%(v / v)(\sim 1746$ 


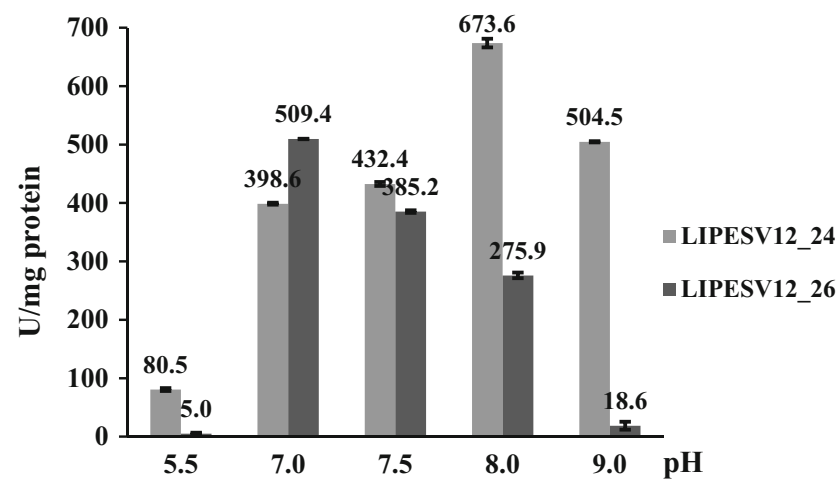

Fig. 5 Hydrolytic activities of LIPESV12 24 and LIPESV12_26. LIPESV12_24 against $p$-NP-butyrate at different $\mathrm{pH}$ values. A wide $\mathrm{pH}$ spectrum of the enzyme activities was demonstrated. The data indicates that the enzymes were neutrophilic or slightly alkaline

and $954.0 \mathrm{U} / \mathrm{mg}$, respectively). Although to a lesser extent than in dibutyl phosphate and acetonitrile, LIPESV12 proteins revealed a high specific activity in different alcohols, such as $30 \%$ of 1,2-propanediol ( $\sim 1039 \mathrm{U} / \mathrm{mg}$ for LIPESV12_24 and $\sim 592 \mathrm{U} / \mathrm{mg}$ for LIPESV12_26) and $10 \%$ ethanol ( $\sim 500$ and $\sim 542 \mathrm{U} / \mathrm{mg}$, respectively) (Table 5). We have tested also ethanol of concentration up to $30 \%(v / v)$, but no activation effects have been observed (data not shown). The LIPESV12_24 enzyme displayed the following activities in methanol: $\sim 685, \sim 945$, and $\sim 769 \mathrm{U} / \mathrm{mg}$ in buffer supplemented with 10,20 , and $30 \%$ ( $\mathrm{vol} / \mathrm{vol})$, respectively. At higher concentrations of methanol, the LIPESV12_24 still revealed a significant activity: $126 \mathrm{U} / \mathrm{mg}$ at $40 \%$ and $127 \mathrm{U} / \mathrm{mg}$ at $50 \%(v / v)$. The similar profile showed also the LIPESV12 26, which in the presence of $30 \%(v / v)$ methanol

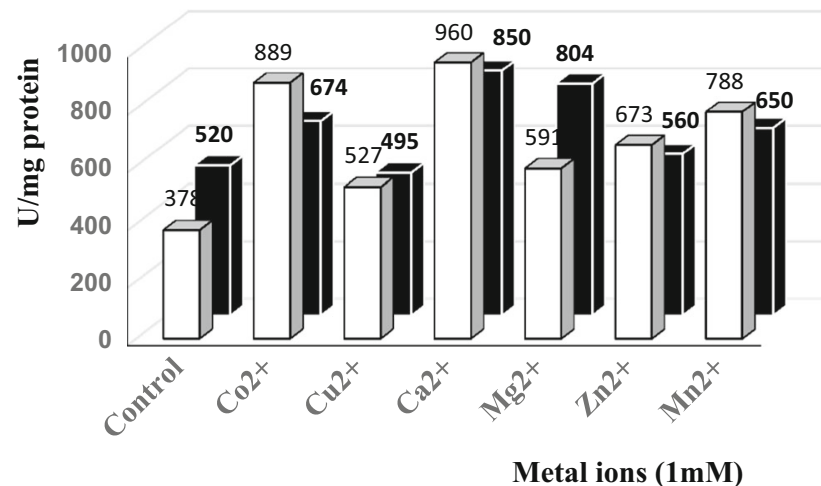

Fig. 6 Influences of bivalent metal ions: $\mathrm{Cu}^{+2}, \mathrm{Co}^{+2}, \mathrm{Zn}^{+2}, \mathrm{Mn}^{+2}, \mathrm{Mg}^{+2}$, and $\mathrm{Ca}^{+2}$ on the activity of LIPESV12 24 (solid bar) and LIPESV12_26 (grey bar). The reaction mixture in each vial was preincubated at $30{ }^{\circ} \mathrm{C}$ in the presence of $1 \mathrm{mM}$ bivalent cation for $5 \mathrm{~min}$. Then, the substrate (1 $\mathrm{mM}$ of $p$-NP-butyrate) was added and activity was measured under standard conditions as described in the "Materials and methods". Both enzymes were activated by the addition of cations: $\mathrm{Co}^{2+}, \mathrm{Ca}^{2+}$, and $\mathrm{Mn}^{2+}$ stimulated activities twofold to threefold towards the substrate in comparison to the control variants. After a longer incubation period (50 min), activities decreased, and in the case of $\mathrm{Cu}^{2+}$ and $\mathrm{Mn}^{+2}$, the activity of LIPESV12 24 dropped from $\sim 527$ and $788 \mathrm{U} / \mathrm{mg}(5 \mathrm{~min}$ of incubation) to $\sim 21$ and $\sim 73 \mathrm{U} / \mathrm{mg}$ (50 min of incubation), respectively had activity of $\sim 914 \mathrm{U} / \mathrm{mg}$ (Table 5). Both LIPESV12 enzymes were also active in $20 \%(v / v)$ isopropanol and developed significant catalytic activities of $\sim 732$ and $\sim 341 \mathrm{U} / \mathrm{mg}$, respectively. The obtained data indicated the metagenomederived new $\alpha / \beta$-hydrolases were capable of retaining their activities in different polar protic and aprotic solvents.

Moreover, we have determined also some kinetic parameters such as Michaelis constant $(\mathrm{Km})$ for the LIPESV12 $\alpha / \beta$ hydrolases. The concentrations of substrates, either $p$-NP-C3 or $p$-NP-C4, varied between 1 and $40 \mathrm{mM}$. Under the standard assay conditions, the $\mathrm{Km}$ for $p$-NP-C4 was $100 \mu \mathrm{M}$ for LIPESV12_26 and $10 \mu \mathrm{M}$ for LIPESV12_24. For the ABO_1197 and ABO_1251, the activity varied as per substrate between $780 \mu \mathrm{M}(p$-NP-C3) and $5 \mu \mathrm{M}(p$-NP-C4), respectively, as reported recently (Tchigvintsev et al. 2014).

\section{Structure prediction analysis for two new hydrolases: LIPESV12_24 and LIPESV12_26}

Both HMMER (Supplementary Table S2) and BLAST indicated that the LIPESV12_26 has a high identity (70-81\%) with the proteins WP_012844996.1 and WP_014067971.1 of Rhodothermus marinus, while LIPESV12_24 exhibited a significantly lower identity (50\%) with $\alpha / \beta$-hydrolases of D. baarsii, delta-proteobacterium NaphS2 (42\%), Desulfatiglans aniline (39\%), and Desulforegula conservatrix (38\%). Meanwhile, the maximum identities to the LIPESV12-9 were found to predict $\alpha / \beta$-hydrolase homologues from Leptonema illini (WP_002775684.1) of $47 \%$ and from Leptospira alstoni (WP_020772540.1) of $42 \%$. A more detailed phylogenetic analysis for the above findings is presented in Fig. 2.

The putative catalytic triads and the reactive centres of the LIPESV12_24 and LIPESV12_26 with 272 and 275 amino acids, respectively, were analysed by using the Phyre 2 and PyMol software available in the abovementioned tools.

The $\alpha / \beta$ fold of different lipases and esterases contains the typical GXSXG. This motif together with a conserved histidine and aspartate (or glutamate) generates the catalytic triad of $\alpha / \beta$-hydrolases (Ollis et al. 1992, Jaeger et al. 1994), which is also present in both V12 hydrolases (see Figs. S7A and B). The possible catalytic triads for LIPESV12 24 and LIPESV12_26 were identified with amino acids S107, D217, and H245, and S94, D218, and H245, respectively. The distances between H245/D217 and H245/D218 in the amino acid sequences of LIPESV12_24 and LIPESV12_26 were 28 and 27 amino acid residues, respectively, similar to the $\mathrm{H}$ and $\mathrm{D} / \mathrm{E}$ distance of about 29 residues reported previously for carboxylic ester hydrolases (Ollis et al. 1992, Jaeger et al. 1994). Based on the three-dimensional model, a shorter distance (3.1 $\AA$ ) between His245 and Asp217 in the V12 24 in comparison to the distance between His245 and Asp218 in its counterpart reached $5.9 \AA$ (Fig. S7A and B). The 
Table 5 Hydrolytic activity of LIPESV12_24 and LIPESV12 26 in solvents

\begin{tabular}{lclc}
\hline $\begin{array}{l}\text { KP buffer }(50 \mathrm{mM}) \\
\text { supplemented with }\end{array}$ & \multicolumn{2}{l}{ Solvent added $(\%, v / v)$} & \multicolumn{2}{l}{ Spec. act. in U/mg (protein $)^{\mathrm{a}}$} \\
\cline { 3 - 4 } & & LIPESV12_24 $^{\text {LIPESV12_26 }}$ \\
\hline KP buffer & None & $360.0 \pm 0.1$ & $524.0 \pm 0.5$ \\
Dibutyl phosphate & 5 & $2600.0 \pm 0.5$ & $955.0 \pm 0.5$ \\
Acetonitrile & 30 & $1746.0 \pm 0.5$ & $954.0 \pm 0.1$ \\
1,2-Propanediol & 30 & $1039.0 \pm 0.5$ & $592.0 \pm 1.0$ \\
Methanol & 30 & $769.0 \pm 0.3$ & $914.0 \pm 1.0$ \\
Isopropanol & 20 & $732.0 \pm 0.1$ & $341.0 \pm 1.0$ \\
Ethanol & 10 & $500.0 \pm 0.5$ & $542.0 \pm 0.1$ \\
\hline
\end{tabular}

${ }^{a}$ Enzyme reactions were carried out as described in the notes of Tables 3 and 4 . The enzyme assay was set up in triplicate, and the results $\pm \mathrm{SD}$ are given in the table polypeptides contain eight $\alpha$-helix turns and six typical $\beta$ sheets, which are also predicted for enzymes of the $\alpha / \beta$-hydrolase_6 superfamily.

\section{Characterization of GLV12_5}

The glycosyl hydrolase selected for this study, GLV12_5, was derived from a fosmid exhibiting the strongest CMC hydrolysis halo (seen as the largest clearance zone in Fig. 1). The homology as well as the phylogenetic relationship of the GLV12_5 was analysed and presented also in the HMMER electronic supplementary table (Table S2) and in Fig. 7. The new glucosyl hydrolase was clustered with some uncharacterized proteins and also some known cellulases and glycosyl hydrolases from Opitutaceae bacterium species (Fig. 7). The PCR product of the gene was cloned using the primer pair GLV12_5-FP and RP with pET46 Ek/LIC adapters, as described in the "Materials and methods" (Table 2). Substrate specificity of the GH enzyme revealed activity towards just one of 16 sugar esters tested, namely, $p$ NP- $\alpha$-arabinopyranose (see Supplementary Table S3). Under the standard assay conditions, the maximal activity was at $35^{\circ} \mathrm{C}$ and $\mathrm{pH} 5.5(\sim 2683 \pm 26 \mathrm{U} / \mathrm{mg})$. Therefore, the enzyme should be considered as $\alpha$-arabinopyranosidase with a quite restricted substrate profile.

\section{Discussion}

The volcanic and geothermal sites are popular subjects for the enzyme biodiversity prospecting, as they harbour microbial communities often composed of extremophiles (Handelsman et al. 1998; Ferrer et al. 2007; Simon and Daniel 2011; Wemheuer et al. 2013; Alcaide et al. 2014). In the present study, we provided a first report on the metagenomic prospecting of hydrolytic enzymes from the shallow hydrothermal vents of the Vulcano Island, Italy, a renowned hot spot of biodiversity of extremophilic microorganisms.
Our results demonstrated that using enzyme activity screening methods, we have successfully obtained numerous hydrolytic enzymes, including lipases and esterases, lactamases/nitrilases, dehalogenases, and glycosyl hydrolases. From DNA sequence analysis of positive fosmid hits, we have predicted and annotated about 200 genes with either full length or with domain homologies to the non-redundant protein databases. From the annotated ORFs, 60 complete proteins deduced have been analysed in more detail. Within this small set of peptide sequences, by performing homology analysis using HMMER and BLAST tools with a low E value cutoff filter, ten known bacterial phyla were predicted as potential hosts of the cloned DNA. The analysis indicated a high taxonomic complexity in the microbial community of the Levante Bay in the Vulcano Island, the enzymatic diversity of which is far from being fully explored. As expected, all affiliated orders were related to marine bacteria, mostly thermophiles from the phyla Proteobacteria, Bacteroidetes, and Acidobacteria (see also Table S1). The organisms donating the eDNA fragments in positive clones were restricted to the organisms typically present in thermophilic, as well as in metal ion- and sulphurrich milieus. The enzymes studied here in detail, LIPESV12_24, LIPESV12_26, and also LIPESV12-9 and GLV12_5, have been derived from the yet uncultured organisms of the orders Desulfarculales and Incertae sedis from order II of Bacteroidetes, and from the uncharacterized protein of some Opitutaceae species (Fig. 2), respectively. The phylogenetic position and homology of both LIPESV12 enzymes with their counterparts from non-redundant protein databases suggested they belong to the $\alpha / \beta$-hydrolase 6 (ABHD6) superfamily. The highest similarity, as well as the closest clustering of LIPESV12 24 to the homologous proteins from marine bacteria of the order Desulfarculales, and of LIPESV12 26 to the R. marinus, and, at the same time, their distant phylogenetic placement one from another (see Fig. 2, Fig. S1, and Table S2), suggests their distinct origin despite a somewhat similar function. Both the LIPESV12 proteins possessed the typical positions of catalytic centres for the 


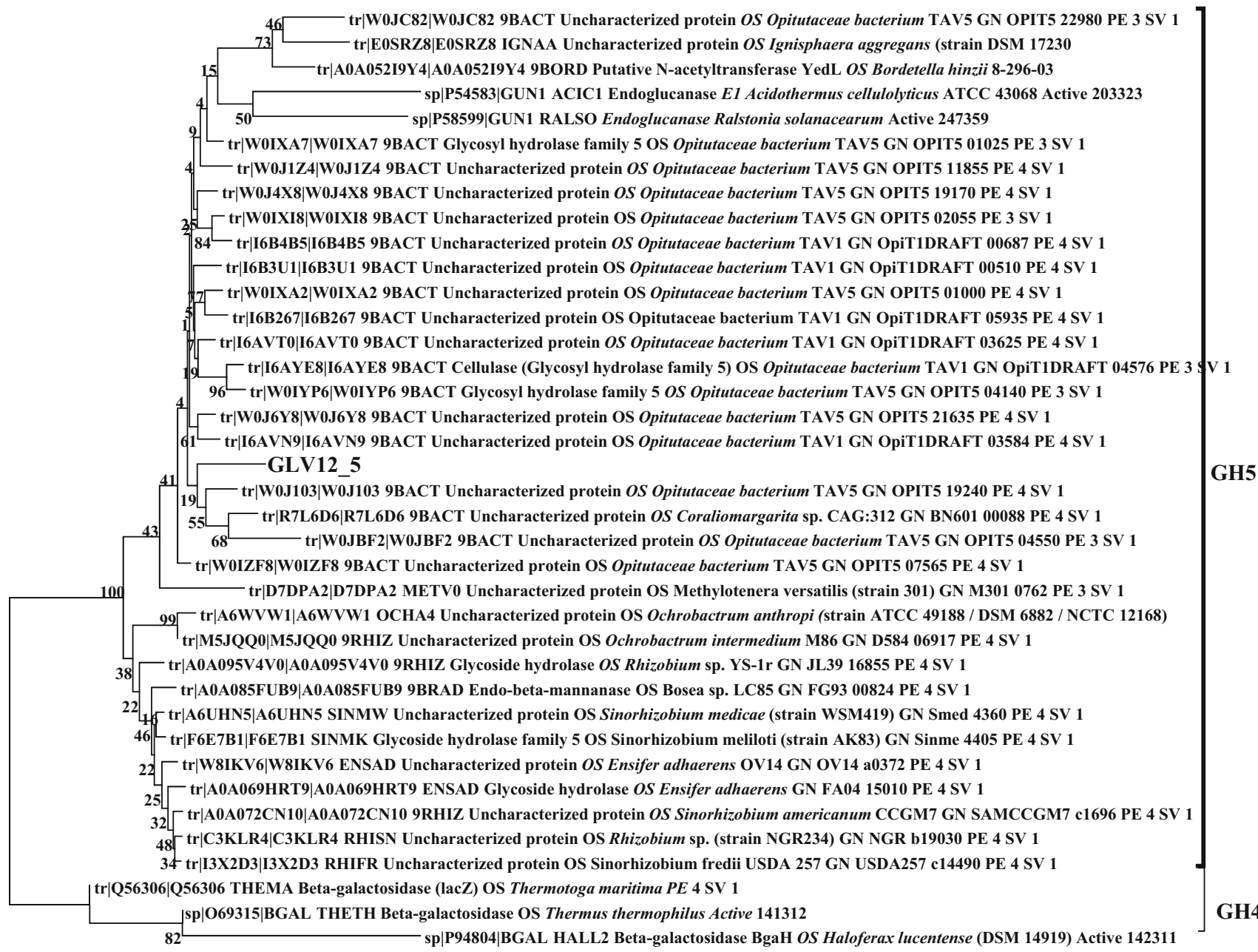

\section{5}

Fig. 7 Phylogenetic position of GLV12 5. The conserved functional domains of each protein were determined using Pfam (http://pfam.xfam. org/search) (Finn et al. 2011). The obtained BLAST data sets of the lowest E values were aligned in MEGA6 (Tamura et al. 2013) using

carboxylesterases with the conserved triads Ser-His-Asp. The identified numbers of helix turns and beta-sheets indicated the similarity of both enzymes to the carboxylic lipase/esterase group, consistent with the data obtained in the primary polypeptide sequence analysis. But the predicted 3D structures of the LIPESV12 proteins were clearly different from the canonical fold of $\alpha / \beta$-hydrolases from other extremozymes such as carboxylic ester hydrolases from hyperthermophiles (Levisson et al. 2009) and the referent proteins in this research: ABO_1197 and ABO_1251 from Alcanivorax bokumensis (see also Tchigvinsev et al. 2014). The nearest homologues of LIPESV12 24 are the $\alpha / \beta$-hydrolase YP 003808833.1 from D. baarsii DSM 2075 (50\% sequence identity), which has been annotated as a lipase (cd00741) with a preference to long-chain esters, and several $\alpha / \beta$-hydrolases from the family 6 (ABHD6), which are active in hydrolysis of long-acyl-chain glycerol esters such as arachidonic glycerol
MUSCLE (Edgar 2004). The tree was constructed by using the neighbour-joining method (Saitou \& Nei 1987) as described in the "Materials and methods"

ester. In the structural models of LIPESV12_24 and LIPESV12_26, the active sites are located in a deep hydrophobic groove and include the putative catalytic triad residues Ser107/94, His245/245, and Asp217/218, respectively. In both active sites, the catalytic serine residues (Ser107 and Ser94) are located on a sharp turn of the protein backbone structure (the nucleophilic elbow), whereas the interacting residues of both catalytic triads (except for Asp218 in LIPESV12_26) are positioned within hydrogen bonding. This suggests that both proteins use the classical Ser-His-Asp catalytic triad mechanism with serine acting as the nucleophile, histidine as the general acid-base, and aspartate helping to neutralize the charge forming on histidine during the catalysis. These active sites appear to be capable of binding acyl esters with short acyl chain lengths. The structural models also suggest that LIPESV12 26 might have a more open active site that is in line with a broader substrate range of this enzyme 
compared to LIPESV12 24. Indeed, in our assays, LIPESV12_26 revealed a wider substrate specificity (hydrolysed 33 from 43 esters tested) compared to LIPESV12-9 (7 from 43) and LIPESV12 24 (15 from 43) (Fig. S7A and Fig. S7B). This was confirmed in experiments using $p$-NP$\mathrm{C} 12$ and $p$-NP-C18 as substrates showing the capacity to hydrolyse longer alkyl esters. In contrast to the ABO proteins and LIPESV12-9, after a long incubation, LIPESV12_24 and LIPESV12_26 were able to hydrolyse significant amounts of long-chain fatty acids, including $p$-NP-C12 and $p$-NP-C16.

To this end, the LIPESV12_enzymes are therefore qualified as carboxylesterase EC 3.1.1.1 with wider substrate specificities. The protein engineering and evolution research for these target proteins basing either on naïve error-prone or on direct mutagenesis with more specific databases and tools, such as 3DM (Kourist et al. 2010), have also been planned for our future research. Furthermore, from a biochemical point of view, the enzymes, especially the LIPESV12_24, pointed at a thermophilic nature of their hosts, retaining the activity even after a short incubation at temperatures near the water boiling point.

The enzymes were tolerant to, and active with, different divalent cations such as calcium, cobalt and magnesium, copper, zinc, and manganese. The three latter metals exhibited inhibition on LIPESV12_24 only after a long incubation. The activity of several metal ions is positively influenced at high temperatures possibly due to ionic bond formation, stabilizing the protein molecules.

The $\mathrm{pH}$ values have a considerable influence on enzyme kinetics due to the influence on the formation or breaking of electrostatic, hydrogen, and other bonds ( $\mathrm{Li}$ et al. 2005). The $\mathrm{pH}$ profile analysis for the enzymes showed their higher activities in the neutral and slightly alkaline ranges. While the LIPESV12_24 was still active at pH 5.5, the LIPESV12_24 at that $\mathrm{pH}$ had almost no activity. This may be explained either by a high buffering capacity of the seawater and thus the selection for neutrophils or by a possible intracellular localization of enzymes.

The use of organic solvents in the industrial biocatalysis offers advantages as compared to the aqueous media due to a higher solubility of hydrophobic substrates, reduced water activity altering the hydrolytic equilibrium, decreased risk of microbial contamination, and others (Sellek and Chaudhuri 1999). Both hydrolases, LIPESV12_24 and LIPESV12_26, could serve as potential candidates for industrial applications, since they kept their stability and activity in organic solvents, even at high concentrations of isopropanol and methanol.

The phylogenetic analysis showed that the representative of GLV12 proteins identified in this study, the GLV12_5, clustered with GH42 and GH5 glycosyl hydrolase groups, which embraced the most cellulose-degrading enzymes. Interestingly, the purified recombinant GLV12_5 protein was highly substrate specific, which revealed activity towards just one of the $16 p$-NP-glycosides tested, namely the $p$-NP- $\alpha$ arabinopyranose. This enzyme should be considered as $\alpha$ arabinopyranosidase (EC 3.2.1 x) with a restricted substrate profile.

The obtained data suggest a high biodiversity of hydrolases in the hydrothermal vents of the Vulcano Island, pointing at a high potential of these environments for mining and exploitation of new industrially relevant enzymes.

Acknowledgments This work was funded by the EU FP7 MicroB3 Research Project (OCEAN-2011-287589) to OVG, HT, and PNG. PNG and OVG acknowledge the Royal Society-Russia Exchange Grant IE130218. SVT thanks the Russian Federal Targeted Program for R and D for support (Grant No. 14.587.21.0007). IVK and AP are thankful to the Russian Foundation of Basic Research (Grant No. 13-04-02157) and Consiglio Nazionale delle Ricerche (Project, Medicina Personalizzata), respectively. We thank EU Horizon 2020 Program for the support of the Project INMARE H2020-BG-2014-2634486. MF thanks grants BIO2011-25012, PIA102014-1 and BIO2014-54494-R from the Spanish Ministry of Economy and Competitiveness. The authors gratefully acknowledge the financial support provided by the European Regional Development Fund (ERDF).

Conflict of interest All authors have declared that they have no conflict of interest. On behalf of all authors, I hereby certify that this article contains the original data from our research activities and is for the first time submitted for publication.

Open Access This article is distributed under the terms of the Creative Commons Attribution 4.0 International License (http:// creativecommons.org/licenses/by/4.0/), which permits unrestricted use, distribution, and reproduction in any medium, provided you give appropriate credit to the original author(s) and the source, provide a link to the Creative Commons license, and indicate if changes were made.

\section{References}

Alcaide M, Stogios PJ, Lafraya A, Tchigvintsev A, Flick R, Bargiela R, Chernikova TN, Reva ON, Hai T, Leggewie CC, Katzke N, La.Cono V, Matesanz R, Jebbar M, Jaeger KE, Yakimov MM, Yakunin AF, Golyshin PN, Golyshina OV, Savchenko A, Ferrer M, The MAMBA Consortium (2015) Pressure adaptation is linked to thermal adaptation in salt-saturated marine habitats. Environ Microbiol 17:332-345. doi:10.1111/1462-2920.12660

Alcaide M, Tchigvintsev A, Martínez-Martínez M, Popovic A, Reva ON, Lafraya Á, Bargiela R, Nechitaylo TY, Matesanz R, CambonBonavita MA, Jebbar M, Yakimov MM, Savchenko A, Golyshina OV, Yakunin AF, Golyshin PN, Ferrer M, The MAMBA Consortium (2014) Identification and characterization of carboxyl esterases of gill chamber-associated microbiota in the deep-sea shrimp Rimicaris exoculata using functional metagenomics. Appl Environ Microbiol. doi:10.1128/AEM.03387-14

Atomi H (2005) Recent progress towards the application of hyperthermophiles and their enzymes. Curr Opin Chem Biol 9: 166-173. doi:10.1016/j.cbpa.2005.02.013

Aziz RK, Bartels D, Best AA, DeJongh M, Disz T, Edwards RA, Formsma K, Gerdes S, Glass EM, Kubal M, Meyer F, Olsen GJ, Olson R, Osterman AL, Overbeek RA, McNeil LK, Paarmann D, 
Paczian T, Parrello B, Pusch GD, Reich C, Stevens R, Vassieva O, Vonstein V, Wilke A, Zagnitko O (2008) The RAST Server: rapid annotations using subsystems technology. BMC Genomics 2008(9): 75. doi:10.1186/1471-2164-9-75

Blunt JW, Copp BR, Keyzers RA, Munro MH, Prinsep MR (2014) Marine natural products. Nat Prod Rep 31(2):160-258. doi:10. 1039/c3np70117d

Boetzer M, Henkel CV, Jansen HJ, Butler D, Pirovano W (2011) Scaffolding pre-assembled contigs using SSPACE. Bioinformatics 15:578-579. doi:10.1093/bioinformatics/btq683

Boetzer M, Pirovano W (2012) Toward almost closed genomes with GapFiller. Genome Biol 25:56. doi:10.1186/gb-2012-13-6-r56

Bornscheuer UT (2002) Microbial carboxyl esterases: classification, properties and application in biocatalysis. FEMS Microbiol Rev 26:73-81. doi:10.1111/j.1574-6976.2002.tb00599.x

Bruins M, Janssen A, Boom R (2001) Thermozymes and their applications. Appl Biochem Biotechnol 90:155-186

Buschke N, Schäfer R, Becker J, Wittmann C (2013) Metabolic engineering of industrial platform microorganisms for biorefinery applications-optimization of substrate spectrum and process robustness by rational and evolutive strategies. Bioresour Technol 135: 544-554. doi:10.1016/j.biortech.2012.11.047

Conesa A, Götz S, García-Gómez JM, Terol J, Talón M, Robles M (2005) Blast2GO: a universal tool for annotation, visualization and analysis in functional genomics research. Bioinformatics 15:3674-3676. doi: 10.1093/bioinformatics/bti610

Cragg GM, Newman DJ (2013) Natural products: a continuing source of novel drug leads. Biochim Biophys Acta 1830:3670-3695. doi:10. 1016/j.bbagen.2013.02.008

Egorova K, Antranikian G (2005) Industrial relevance of thermophilic Archaea. Curr Opin Microbiol 8:649-655. doi:10.1016/j.mib.2005. 10.015

Edgar RC (2004) MUSCLE: multiple sequence alignment with high accuracy and high throughput. Nucleic Acids 32(5):1792-1797

Elleuche S, Schröder C, Sahm K, Antranikian G (2014) Extremozymesbiocatalysts with unique properties from extremophilic microorganisms. Curr Opin Biotechnol 29:116-123. doi:10.1016/j.copbio. 2014.04.003

Erickson B, Nelson JE, Winters P (2012) Perspective on opportunities in industrial biotechnology in renewable chemicals. Biotechnol $\mathrm{J} 7$ : 176-185. doi:10.1002/biot.201100069

Ferrer M, Golyshina OV, Chernikova TN, Khachane AN, Martin dos Santos VAP, Yakimov MM, Timmis KM, Golyshin PN (2005) Microbial enzymes mined from the Urania deep-sea hypersaline anoxic basin. Chem Biol 12:895-904. doi:10.1016/j.chembiol. 2005.05.020

Ferrer M, Golyshina O, Beloqui A, Golyshin PN (2007) Mining enzymes from extreme environments. Curr Opin Microbiol 10:207-214. doi: 10.1016/j.mib.2007.05.004

Finn RD, Clements J, Suggest SR (2011) Interactive sequence similarity searching. Nucleic Acids Research (2011) Web Server Issue 39: W29-W37.

Frazzetto G (2003) White biotechnology: the application of biotechnology to industrial production holds many promises for sustainable development, but many products still have to pass the test of economic viability. EMBO 4:835-837. doi:10.1038/sj.embor. embor928

Glöckner FO, Joint A (2010) Marine microbial genomics in Europe: current status and perspectives. Microb Biotechnol 3:523-530. doi:10.1111/j.1751-7915.2010.00169.x

Grawe GF, de Oliveira TR, de Andrade NE, Moccelini SK, Terezo AJ, Soares MA, Castilho M (2015) Electrochemical biosensor for carbofuran pesticide based on esterases from Eupenicillium shearii FREI-39 endophytic fungus. Biosens Bioelectron 63:407-413. doi: 10.1016/j.bios.2014.07.069
Gupta R, Rathi P, Gupta N, Bradoo S (2002) Lipase assays for conventional and molecular screening: an overview. Biotechnol Appl Biochem 37:63-71. doi:10.1042/BA20020059

Handelsman J, Rondon MR, Brady SF, Clardy J, Goodman RM (1998) Molecular biological access to the chemistry of unknown soil microbes: a new frontier for natural products. Chem Biol 5:245-249. doi:10.1016/S1074-5521(98)90108-9

He MX, Wu B, Qin H, Ruan ZY, Tan FR, Wang JL, Shui ZX, Dai LC, Zhu QL, Pan K, Tang XY, Wang WG, Hu QC (2014) Zymomonas mobilis: a novel platform for future biorefineries. Biotechnol.Biofuels 7:101. doi:10.1186/1754-6834-7-101

Hall TA (1999) BioEdit: a user-friendly biological sequence alignment editor and analysis program for Window 95/98/NT. Nucleic Acids Symp Ser 41:95-98

Jaeger KE, Ransac S, Dijkstra BW, Colson C, Vanheuvel M, Misset O (1994) Bacterial lipases. FEMS Microbiol Rev 15:29-63. doi:10. 1111/j.1574-6976.1994.tb00121.x

Kennedy J, O'Leary ND, Kiran GS, Morrissey JP, O'Gara F, Selvin J, Dobson ADW (2011) Functional metagenomic strategies for the discovery of novel enzymes and biosurfactants with biotechnological applications from marine ecosystems. J Appl Microbiol 111: 787-799. doi:10.1111/j.1365-2672.2011.05106.x.

Khalameyzer V, Fischer I, Bornscheuer UT, Altenbuchner J (1999) Screening, nucleotide sequence, and biochemical characterization of an esterase from Pseudomonas fluorescens with high activity towards lactones. Appl Environ Microbiol 65:477-482

Kublanov IV, Perevalova AA, Slobodkina GB, Lebedinsky AV, Bidzhieva SK, Kolganova TV, Kaliberda EN, Rumsh LD, Haertlé T, Bonch-Osmolovskaya EA (2009) Biodiversity of thermophilic prokaryotes with hydrolytic activities in hot springs of Uzon Caldera, Kamchatka (Russia). Appl Environ Microbiol 75:286291. doi:10.1128/AEM.00607-08

Kourist R, Jochens J, Bartsch S, Kuipers R, Padhi SK, Gall M, Böttcher D, Joosten HJ, Bornscheuer UT (2010) The $\alpha / \beta$-Hydrolase Fold 3DM Database (ABHDB) as a tool for protein engineering. ChemBioChem 11:1635-1643

Levin LA, Sibuet M (2012) Understanding continental margin biodiversity: a new imperative. Annu Rev Mar Sci 4:79-112(Carlson CA, Giovannoni SJ, Eds). doi:10.1146/annurev-marine-120709-142714.

Levisson M, van der Oost J, Kengen SWM (2009) Carboxylic ester hydrolases from hyperthermophiles. Extremophiles 13:567-581. doi:10.1007/s00792-009-0260-4

Li WF, Zhou XX, Lu P (2005) Structural features of thermozymes. Biotechnol Adv 23:271-281. doi:10.1016/j.biotechadv.2005.01.002

López-López O, Cerdán ME, González Siso MI (2014) New extremophilic lipases and esterases from metagenomics. Curr Protein Pept Sci 15:445-455. doi:10.2174/ 1389203715666140228153801

Nogi Y, Kato C (1999) Taxonomic studies of extremely barophilic bacteria isolated from the Mariana Trench and description of Moritella yayanosii sp. nov., a new barophilic bacterial isolate. Extremophiles 3:71-77

Ollis D, Cheah E, Cygler M, Dijkstra B, Frolow F, Franken S, Harel M, Remington S, Silman I, Schrag J (1992) The $\alpha / \beta$-hydrolase fold. Protein Eeng 5:197-211. doi:10.1093/protein/5.3.197

Overbeek R, Olson R, Pusch GD, Olsen GJ, Davis JJ, Disz T, Edwards RA, Gerdes S, Parrello B, Shukla M, Vonstein V, Wattam AR, Xia F, Stevens R (2014) The SEED and the Rapid Annotation of microbial genomoes using Subsystem Technology (RAST). Nucleic Acids Res 42:206-214. doi:10.1093/nar/gkt1226

Panda T, Gowrishankar BS (2005) Production and applications of esterases. Appl Microbiol Biotechnol 67:160-169

Pérez D, Kovacic F, Wilhelm S, Jaeger KE, Garcia MT, Ventosa A, Mellado E (2012) Identification of amino acids involved in hydrolytic activity of lipase LipBL from Marinobacter lipolyticus. Microbiology 158:2192-2203. doi:10.1099/mic.0.058792-0. 
Poli A, Anzelmo G, Nicolaus B (2010) Bacterial exopolysaccharides from extreme marine habitats: production, characterization and biological activities. Mar Drugs 3(8):1779-1802. doi:10.3390/ md8061779

Saitou N, Nei M (1987) The neighbor-joining method: a new method for reconstructing phylogenetic trees. Mol Biol Evol 4:406-425

Schmieder R, Edwards R (2011) Fast identification and removal of sequence contamination from genomic and metagenomic datasets. PLoS One 6(3):e17288. doi:10.1371/journal.pone.0017288

Sellek GA, Chaudhuri JB (1999) Biocatalysis in organic media using enzymes from extremophiles. Enzym Microb Tech 25:471-482

Simon C, Daniel R (2011) Metagenomic analyses: past and future trends. Appl Environ Microbiol 77:1153-1161. doi:10.1128/AEM.02345-10

Tamura K, Stecher G, Peterson D, Filipski A, Kumar S (2013) MEGA6: Molecular Evolutionary Genetics Analysis Version 6.0. Mol Biol Evol 30(12):2725-2729. doi:10.1093/molbev/mst197

Tchigvintsev A, Tran H, Popovic A, Kovacic F, Brown G, Flick R, Hajighasemi M, Egorova O, Somody JC, Tchigvintsev D, Khusnutdinova A, Chernikova TN, Golyshina OV, Yakimov MM,
Savchenko A, Golyshin PN, Jaeger KE, Yakunin AF (2014) The environmental shapes microbial enzymes: five cold-active and salt resistant carboxylesterases from marine metagenomes. Appl Microbiol Biotechnol 99(5):2165-2178. doi:10.1007/s00253-0146038-3

Wemheuer B, Taube R, Alkyol P, Wemheuer F, Daniel R (2013) Microbial diversity and biochemical potential encoded by thermal spring metagenomes derived from the Kamchatka Peninsula. Archaea 2013:1-13. doi:10.1155/2013/136714

White JR, Escobar-Paramo P, Mongodin EF, Nelson KE, DiRuggiero J (2008) Extensive genome rearrangements and multiple horizontal gene transfers in a population of Pyrococcus isolates from Vulcano Island, Italy. Appl Environ Microbiol 74(20):6447-6451. doi:10. 1128/AEM.01024-08.

Yu J (2014) Bio-based products from solar energy and carbon dioxide. Trends Biotechnol 32:5-10. doi:10.1016/j.tibtech.2013.11.001

Zhang C, Kim SK (2010) Research and application of marine microbial enzymes: status and prospects. Mar Drugs 8:1920-1934. doi:10. 3390/md8061920 